\title{
Universiteit
}

Leiden

The Netherlands

\section{Writing histories of contemporary Africa}

Ellis, S.D.K.

\section{Citation}

Ellis, S. D. K. (2002). Writing histories of contemporary Africa. The Journal Of African History, 43(1), 1-26. Retrieved from https://hdl.handle.net/1887/9513

Version: $\quad$ Not Applicable (or Unknown)

License:

Downloaded from: https://hdl.handle.net/1887/9513

Note: To cite this publication please use the final published version (if applicable). 
Fournal of African Hustory, 43 (2002), pp $1-26$ (C) 2002 Cambridge University Press

tran Rear ICHARD REID in Around

rogan 3RETT SHADLE ,ch-

, ch-

3NEIT-SIEVERS d War.

Y H. PARSONS $y$ of Nontetha AH GAITSKELI contents.

ANN O'HEAR uccessors.

RTIN A. KLEIN TOYIN FALOLA Polztics, IRD RATHBONE istory of the AN PHIMISTER I899-I940. SUSAN KENYON zatzon and IAN SADOWSKY Strategies $m$ 3ERT L. TIGNOR Letters from

IVOR WILKS nd Waluguru AVID MAXWELL inging

JRY H. MADDOX INDA HEYWOOD $h$ and

PHER CLAPHAM orthern Ghana MARK BREUSERS

ANDRA PANGETI

cuety and RISTOPHER FYFE olume I: HONY CLAYTON ROB SKINNER A. B. SIKHONDZE

\section{WRITING HISTORIES OF CONTEMPORARY AFRICA*}

\author{
BY STEPHEN ELLIS \\ Afrika-Studiecentrum, Leiden
}

ABSTRACT: This essay argues that historians need to engage with the history of contemporary Africa both as a way of throwing new light on Africa's more remote past and as a way of understanding the present. The paper discusses two types of problem involved in such an enterprise. The first is the identification of the most fruitful themes for investigation. The second is the sources that may be used.

KEY WORDS: Historiography, post-colonial, sources.

FORTY years, or nearly two generations, have passed since the majority of African states became independent. This passage of time presses historians to consider how they might write histories of Africa since independence. Not least among those who might find such work useful are historians of earlier periods, if only for the functional reason that every piece of the past forms a context for other pieces of the past. Histories of colonial times, for example, are inevitably coloured by what we think we know about what happened next. Conversely, some keen observers of contemporary Africa, although not motivated by any professional commitment to historical inquiry, nevertheless feel impelled to investigate the recent past as a means of understanding phenomena that are apparent today, in an effort to produce a more convincing explanation than is currently available of how things came to be the way they are. ${ }^{1}$ Analyses of this sort may be more relevant to the rest of the world than is generally realized. ${ }^{2}$

In short, both historians and specialists from other disciplines sometimes find unsatisfactory the models of historical explanation that are available to them when they are studying Africa's recent past and its present. This is unsurprising inasmuch as many of the contemporary histories written in the r 960 s and 1970 s reflected the political preoccupations considered most urgent at that time, using the intellectual models that seemed most convincing. ${ }^{3}$ For all their achievement, such works by and large no longer speak to concerns that appear important today, as we shall see, and yet they have not been replaced by a new generation of contemporary histories rooted in

* I am grateful for comments on a previous draft of this paper by David Killingray and by two anonymous referees.

1 E.g. Mahmood Mamdan1, Citizen and Subject : Contemporary Africa and the Legacy of Late Colonialssm (Princeton, 1996).

2 Florence Bernault, 'L'Afrique et la modernité des sciences sociales', Vingtième siècle, $7 \circ(2001), 127-38$

3 This includes much of the work of Basil Davidson, for example, probably the bestselling historian of contemporary Africa in English over a long period. On the key themes of the rg6os, Terence Ranger (ed.), Emerging Themes in African History (Natrobi, 1968). 


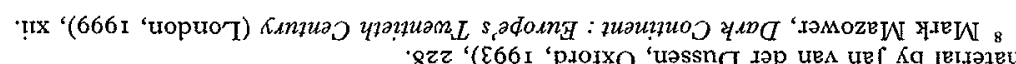

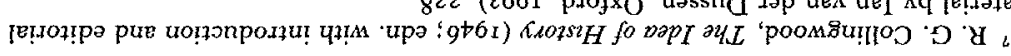

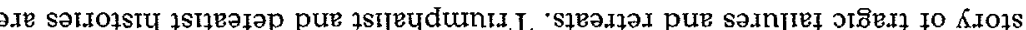

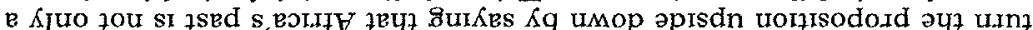

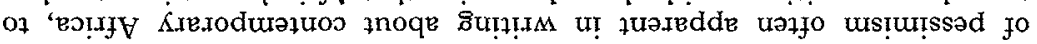

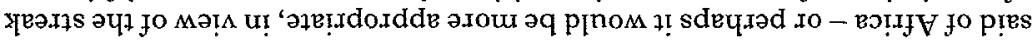

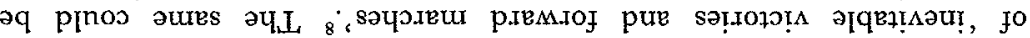

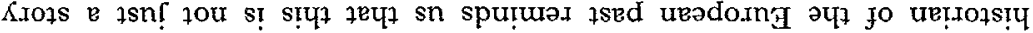

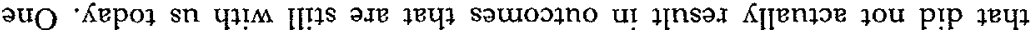
inq portum

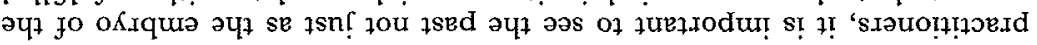

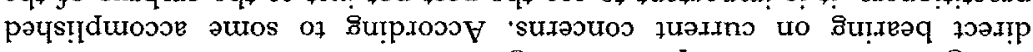

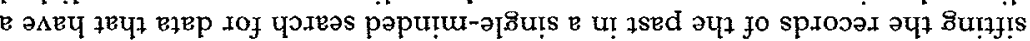

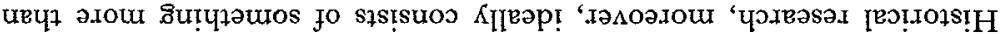

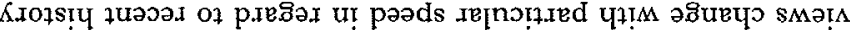

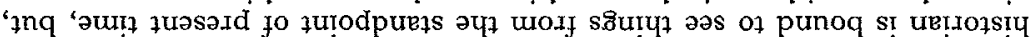

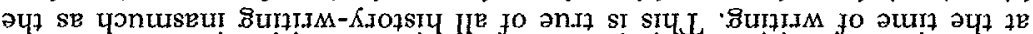

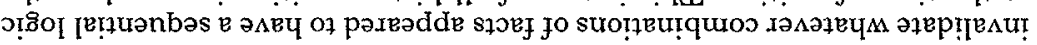

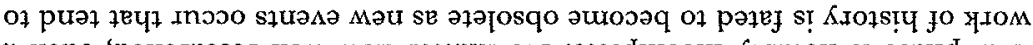

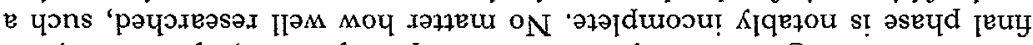

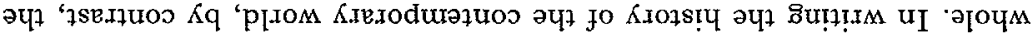

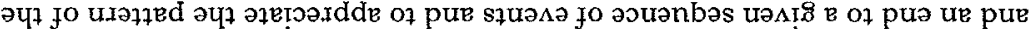
8

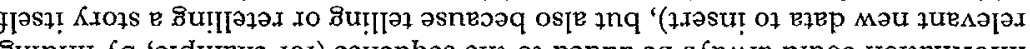

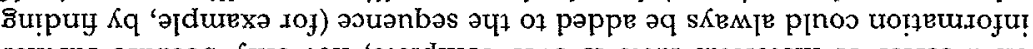

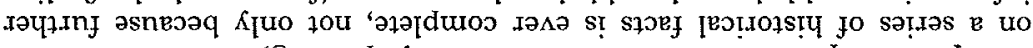

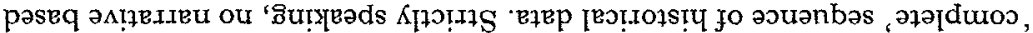

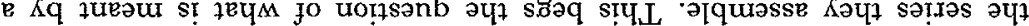

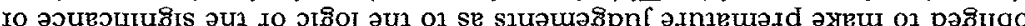
วroja.ə

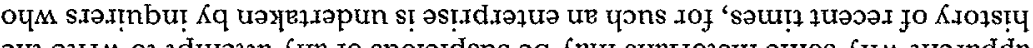

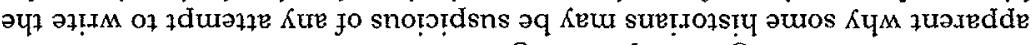

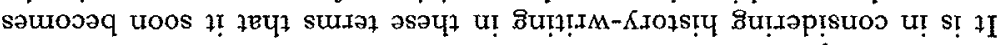

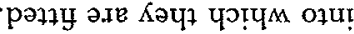

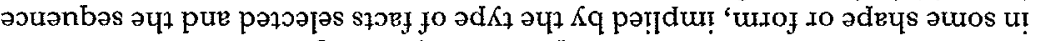

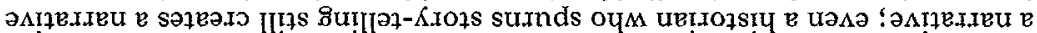

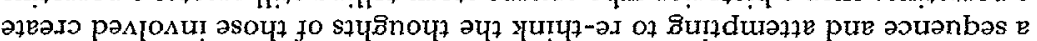

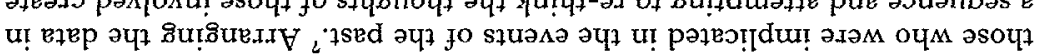

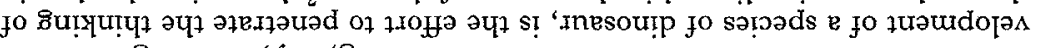

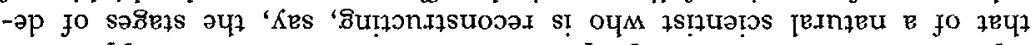

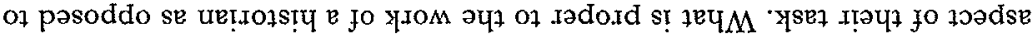

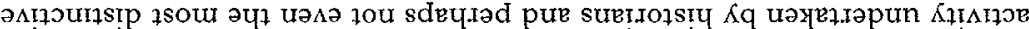

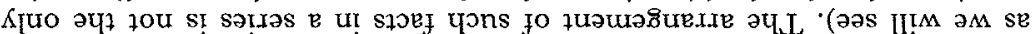

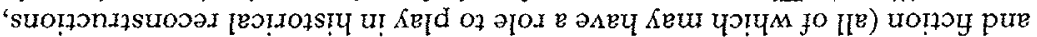
K.rourau '

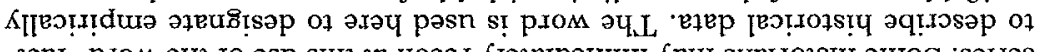

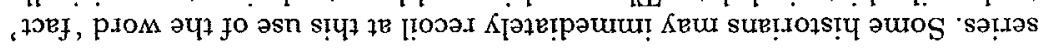

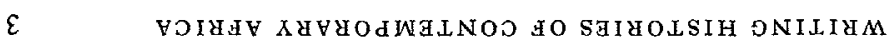

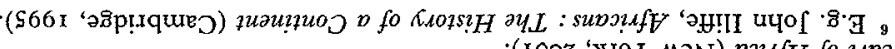

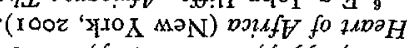

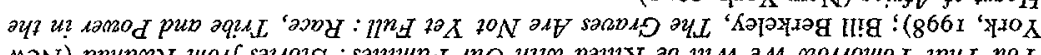
MəN) ppuvmy uoif sat107S : sal?zun

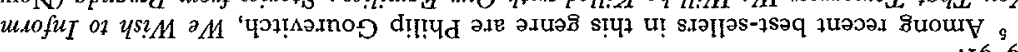

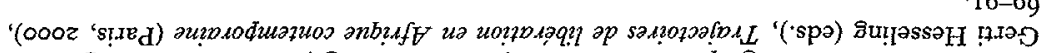

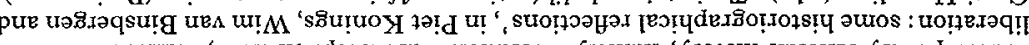

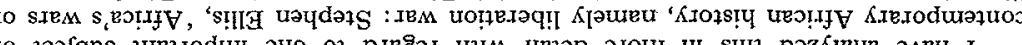

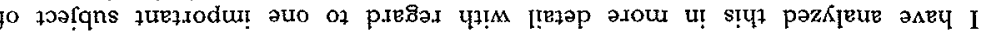

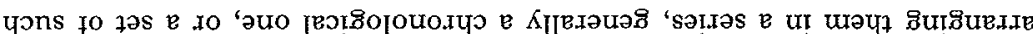

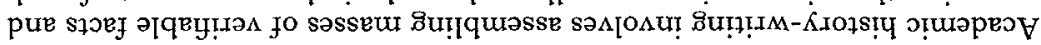

XYOLSIH XYVZOANGLNOD HO SNATGOUd

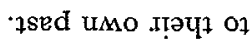

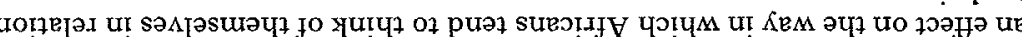

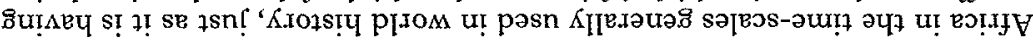

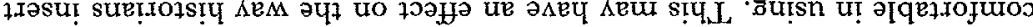

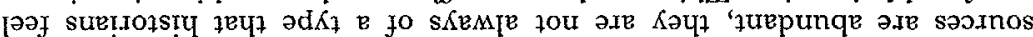

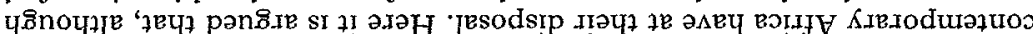
jo surị.

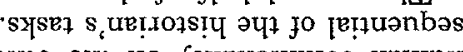

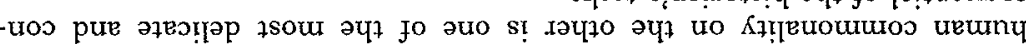

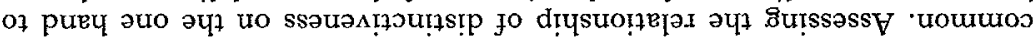

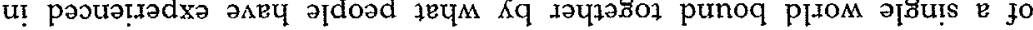

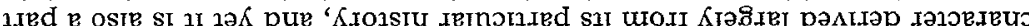
1.80 a !n

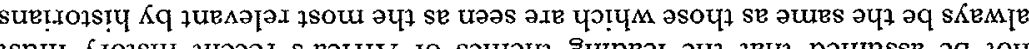

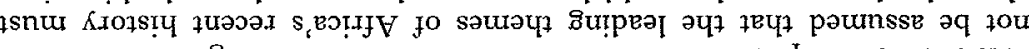

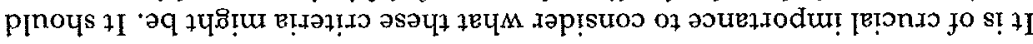

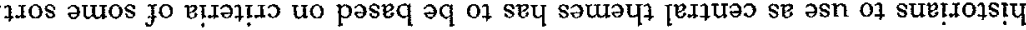

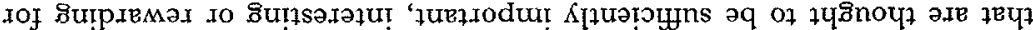

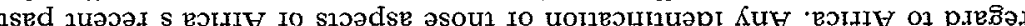

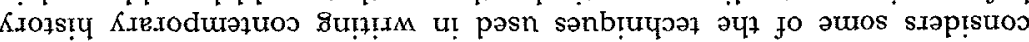

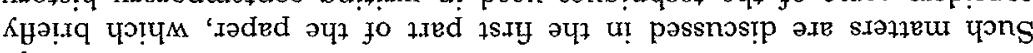

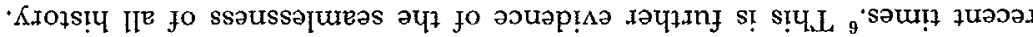

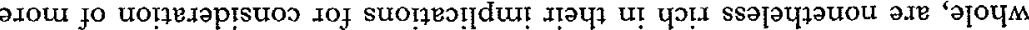

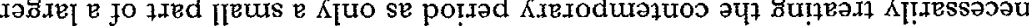

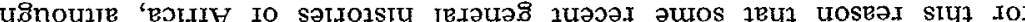

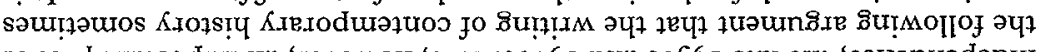

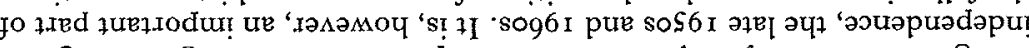
fo วธิв иәр

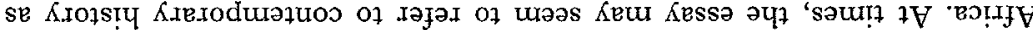

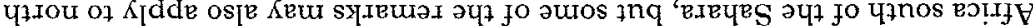

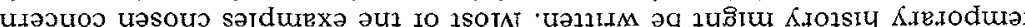

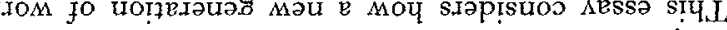
$i^{-K I O I S T Y}$

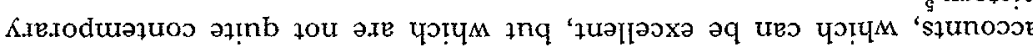
, słs!̣ SITTA NGHdBLS 


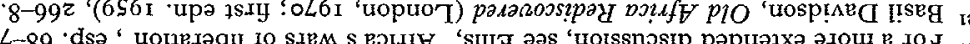

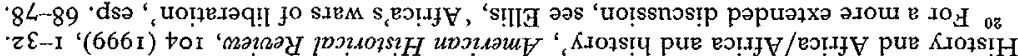

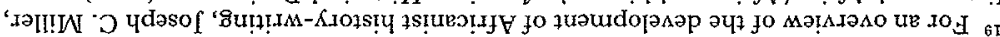

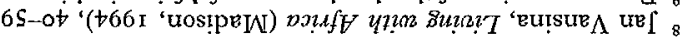

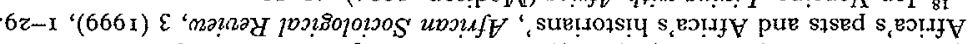

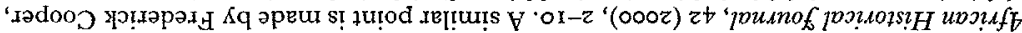

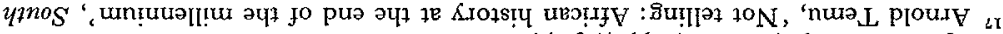

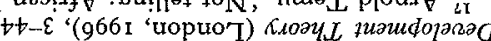

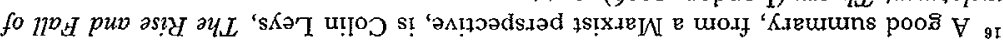

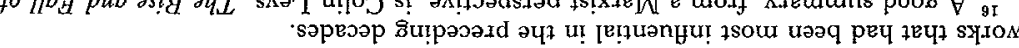

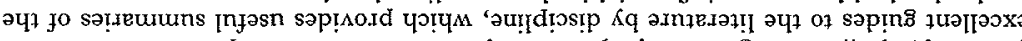

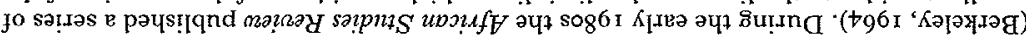

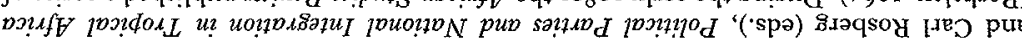

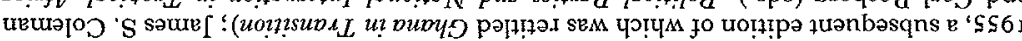

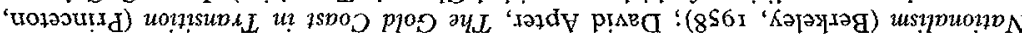

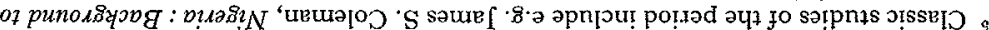

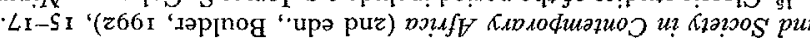

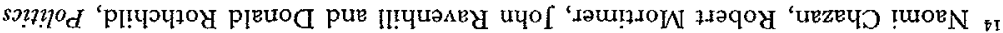

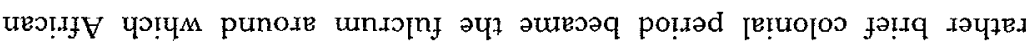

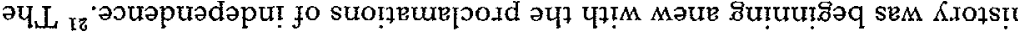

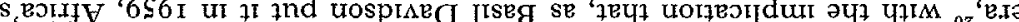

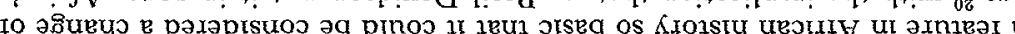

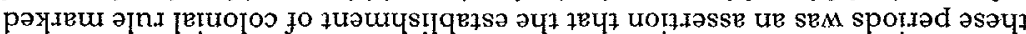

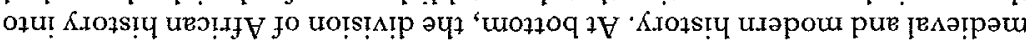

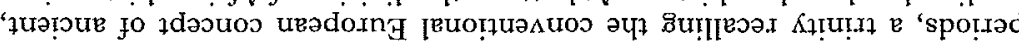

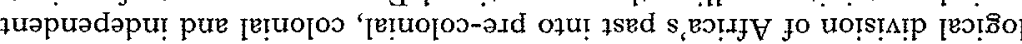

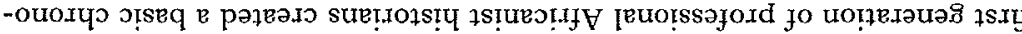

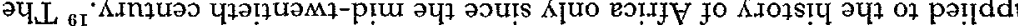

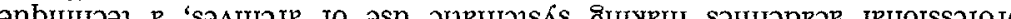

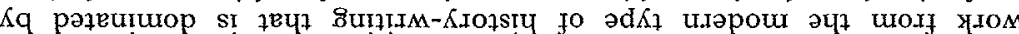

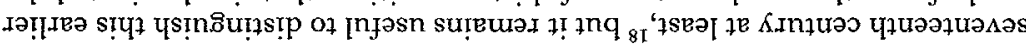

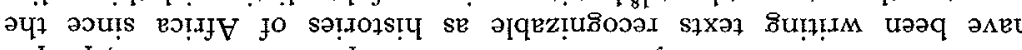
ә]doad 'วans әq o, 'әu!̣

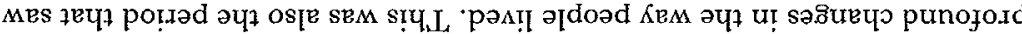

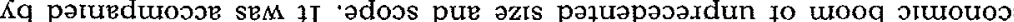

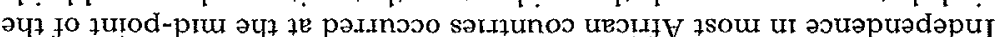

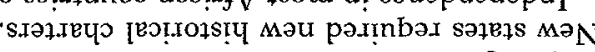

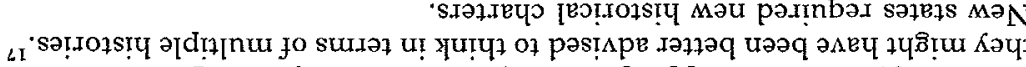

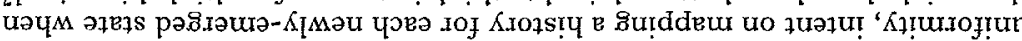

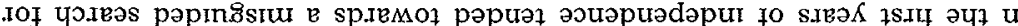

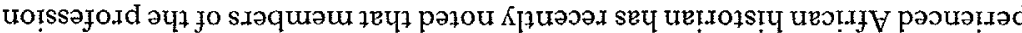

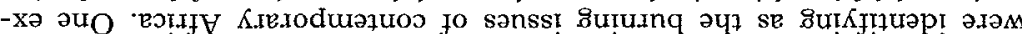

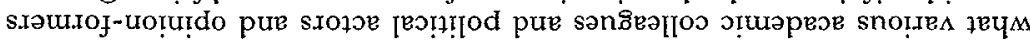

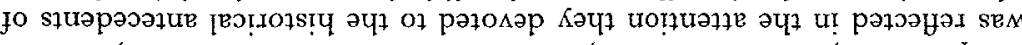

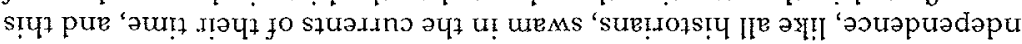

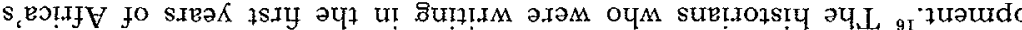

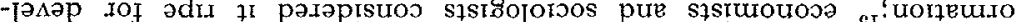

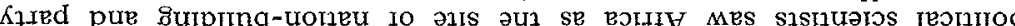

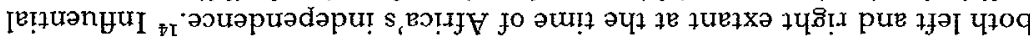

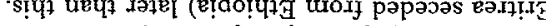

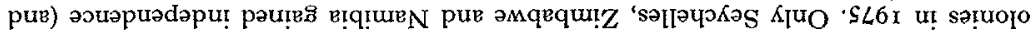

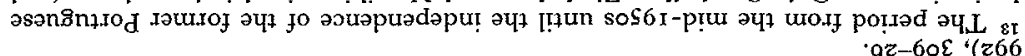

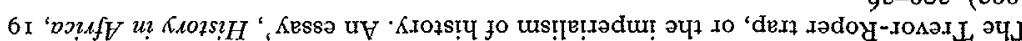

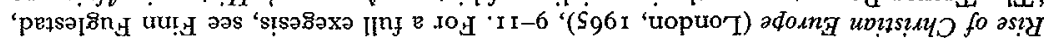

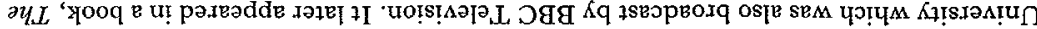

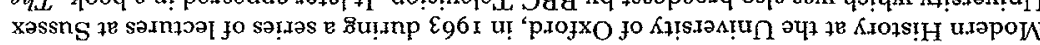

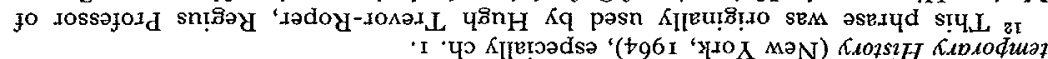

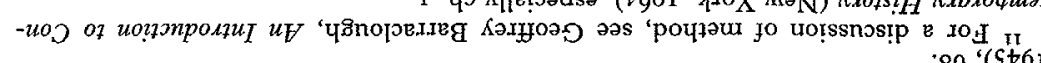

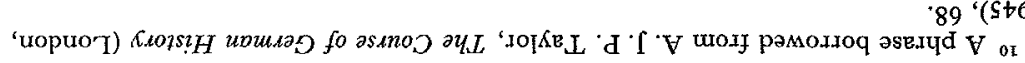
pIgI

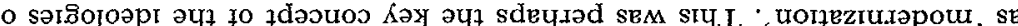
pəq!ฺว

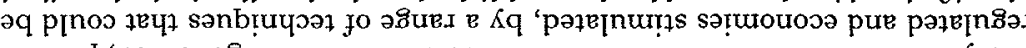

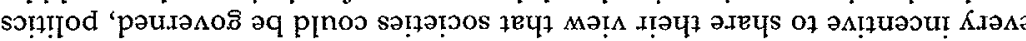

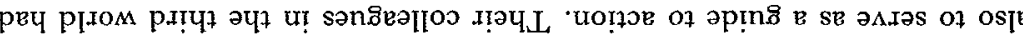

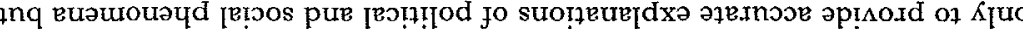

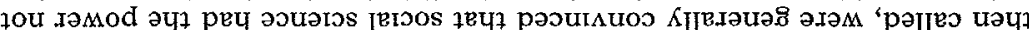

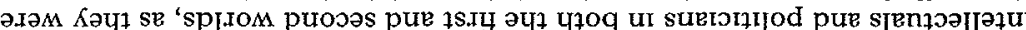

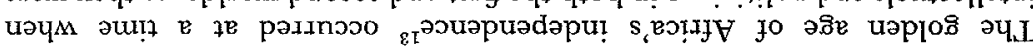

SHINHA TYOIYOLSIH

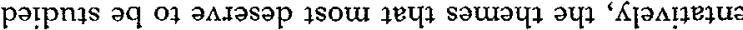

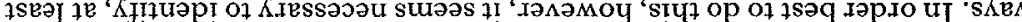

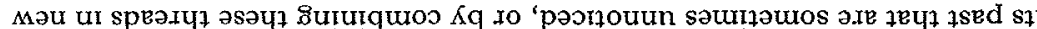

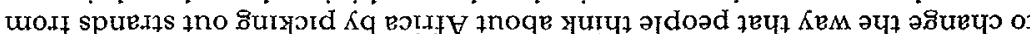

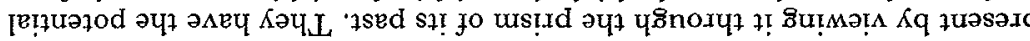

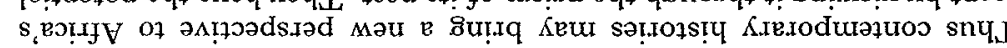

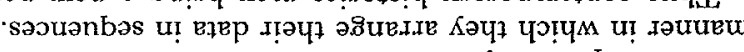

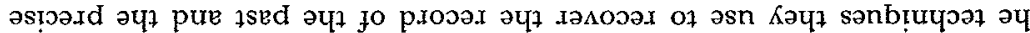

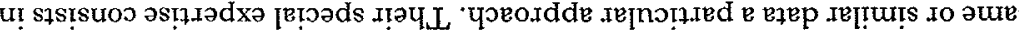

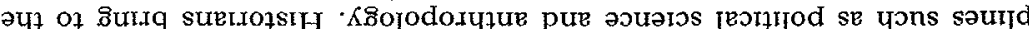
-

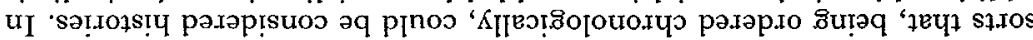

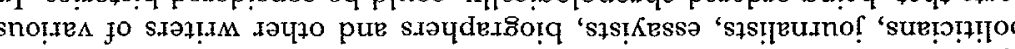

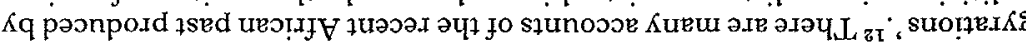

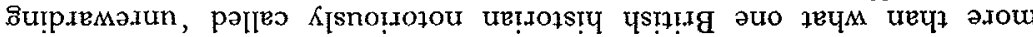

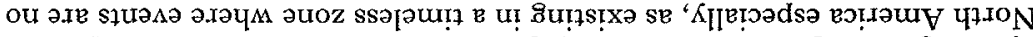

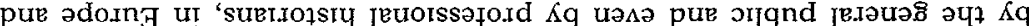
'Uəə⿻

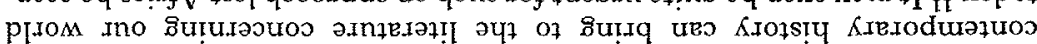

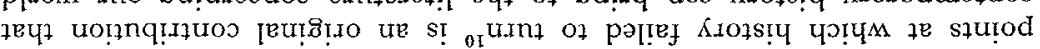

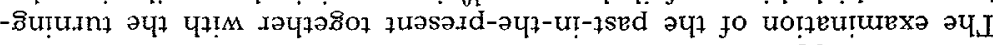

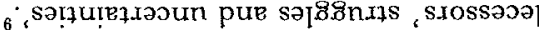

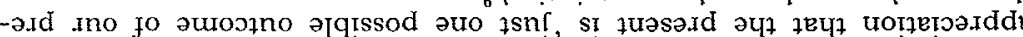
ue si yұ. 


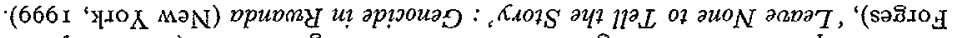

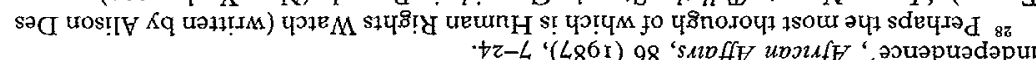

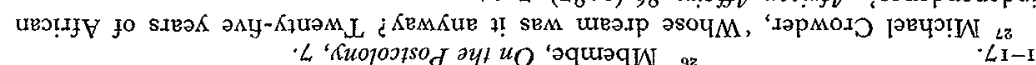

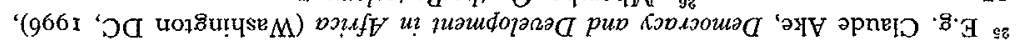

иәр

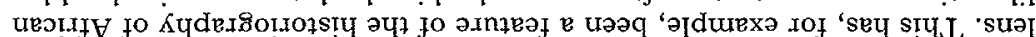
p

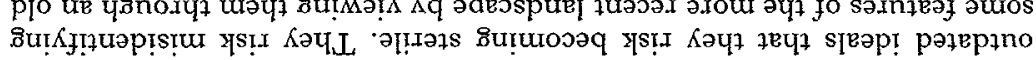

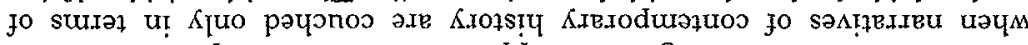

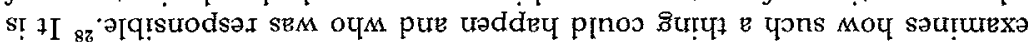

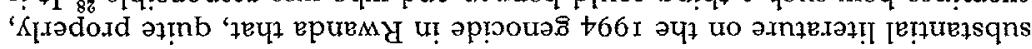

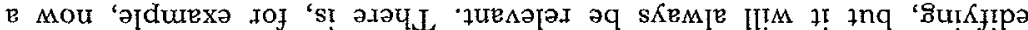

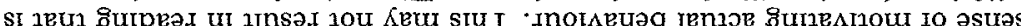

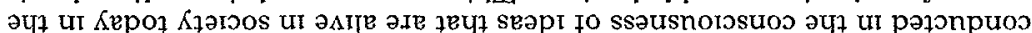

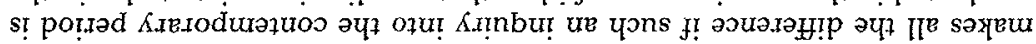

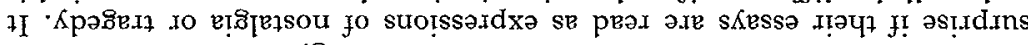

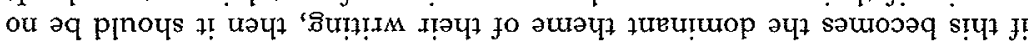

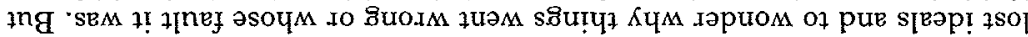

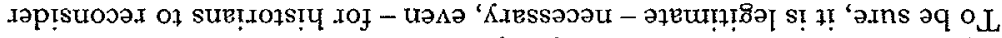

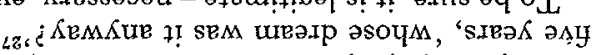

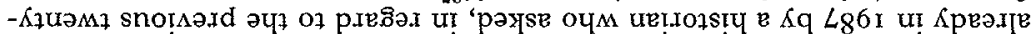

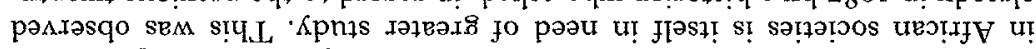

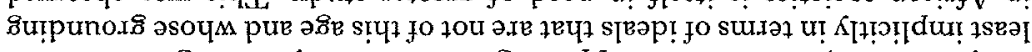

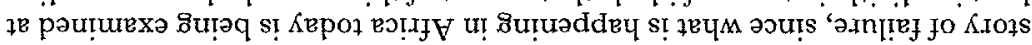

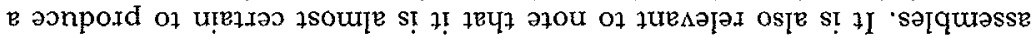

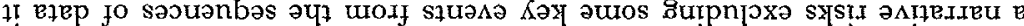

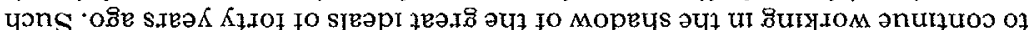

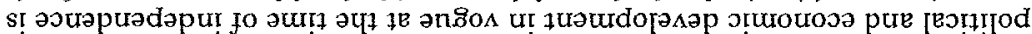

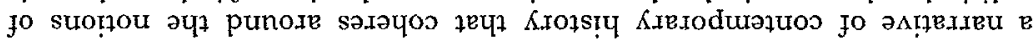

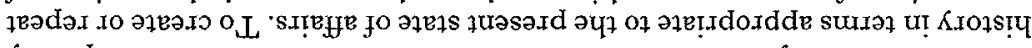

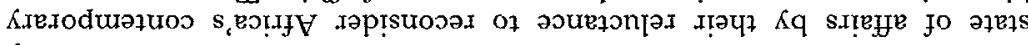

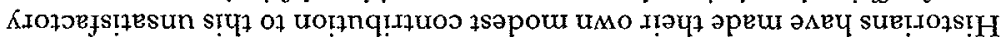

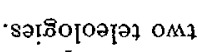

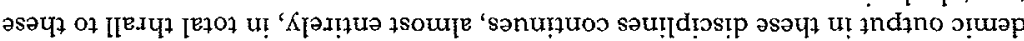

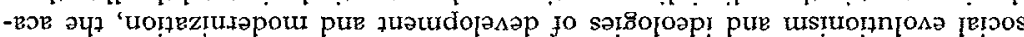

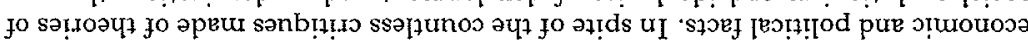

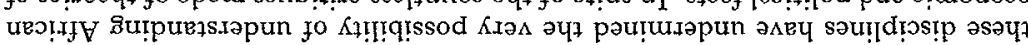

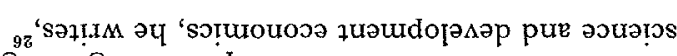

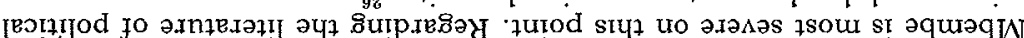

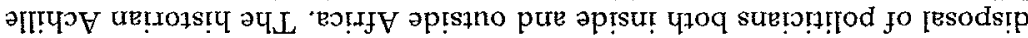

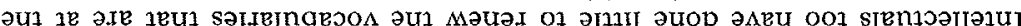
गu० sromsaoun paran Jo a

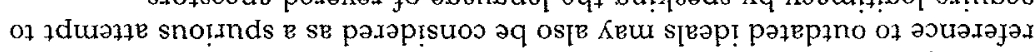

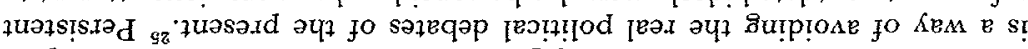

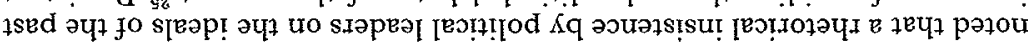

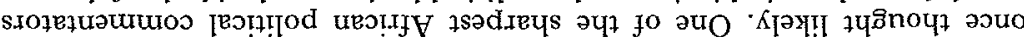

9 '(t66i 'roopuo 7 )

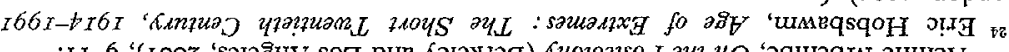

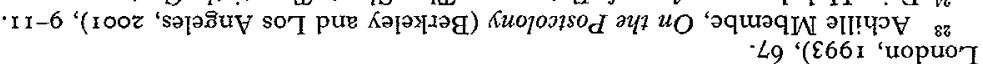

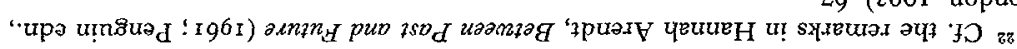

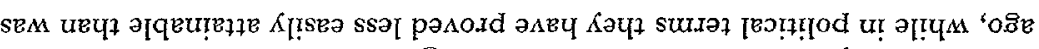

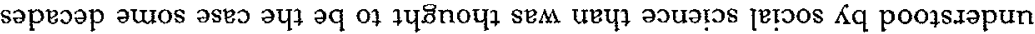

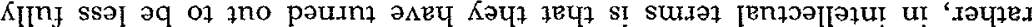

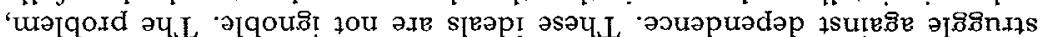

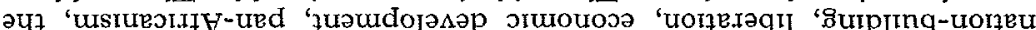

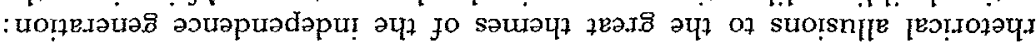

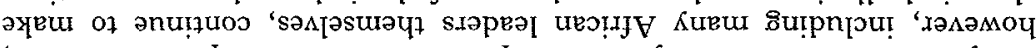

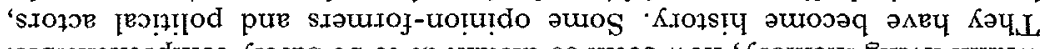

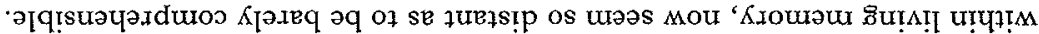

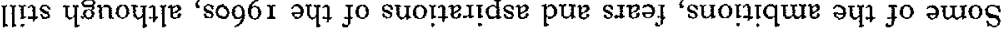
- Iartiga sibas maj p syuo

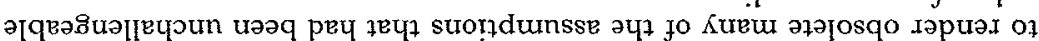

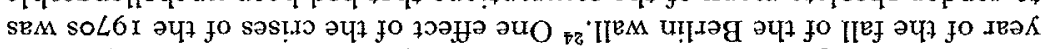

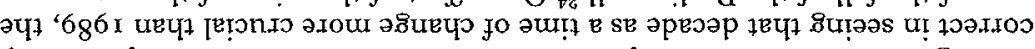

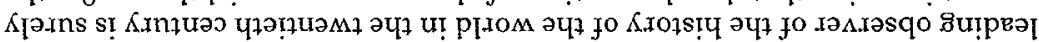

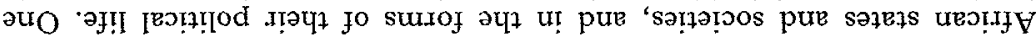

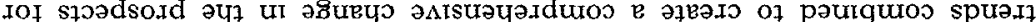

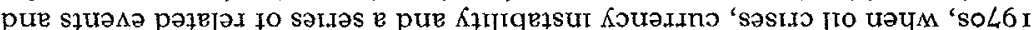

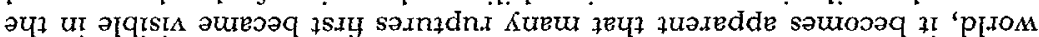

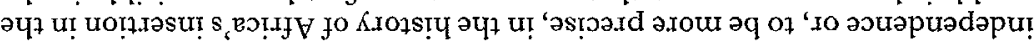

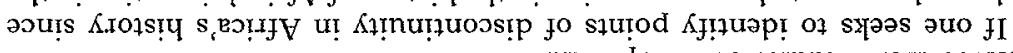

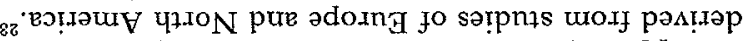

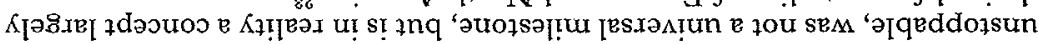

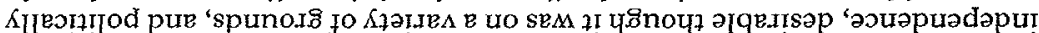

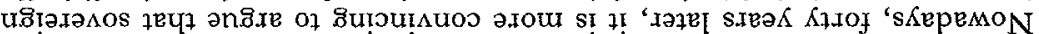

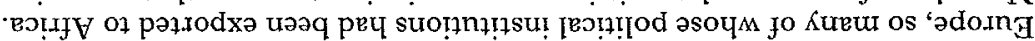

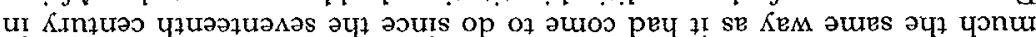

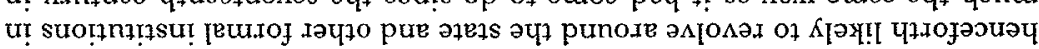

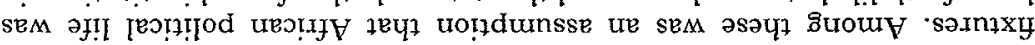

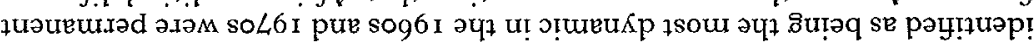

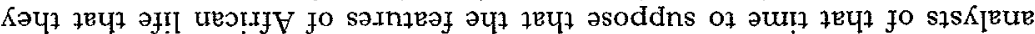

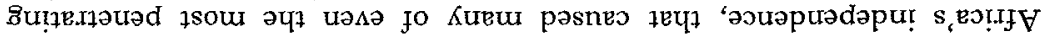

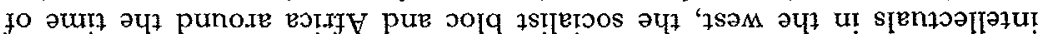

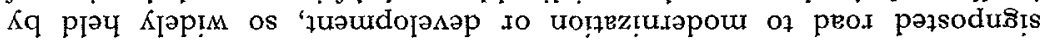

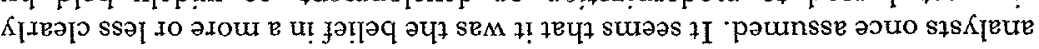

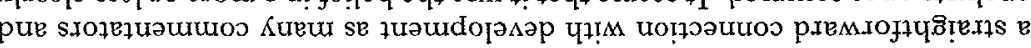

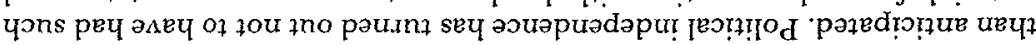

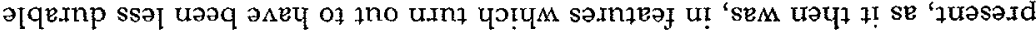

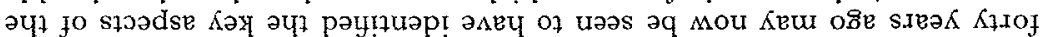

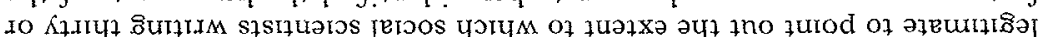

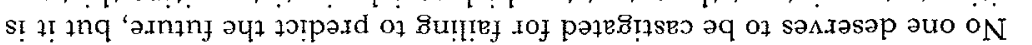

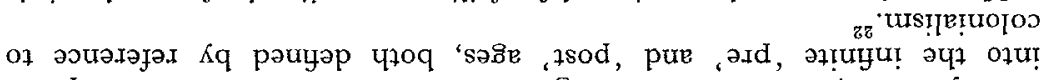
ұUiod ұвч SITTI NAHAJIS 


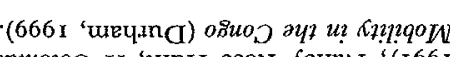

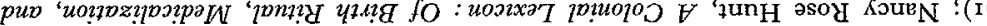

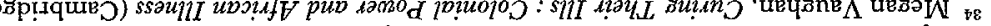

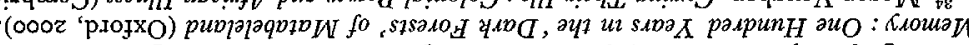

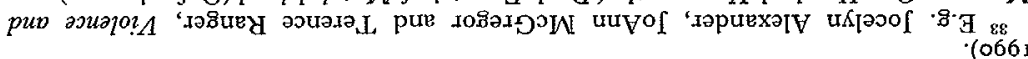

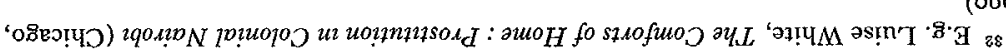

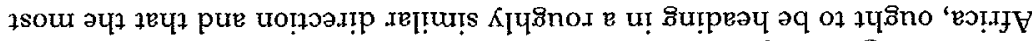

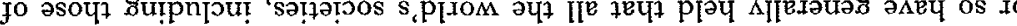

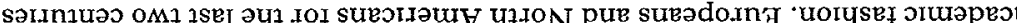

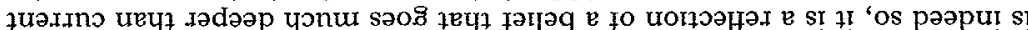

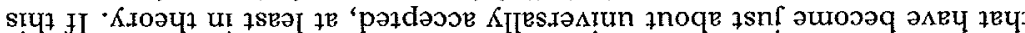

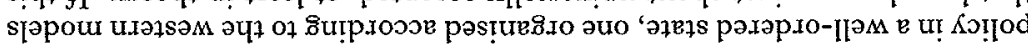

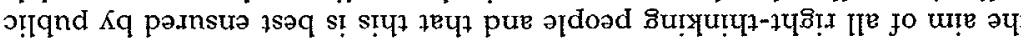

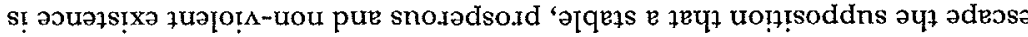

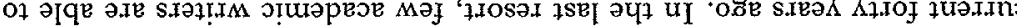

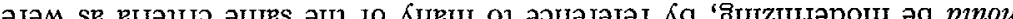

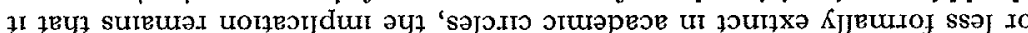

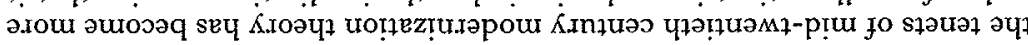

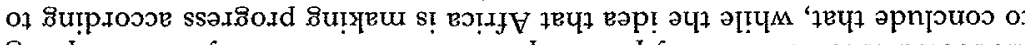

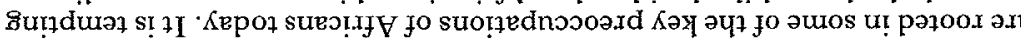

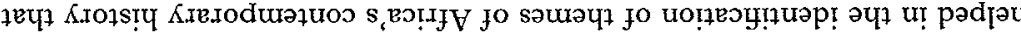

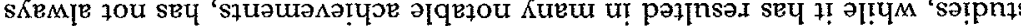

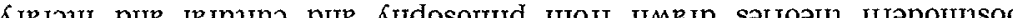

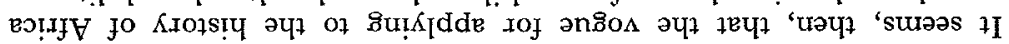

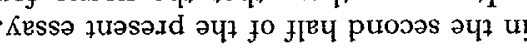

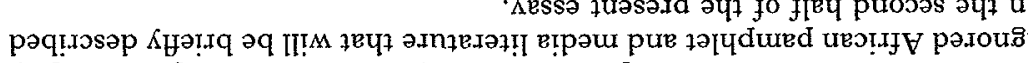

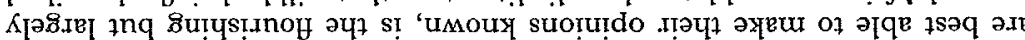

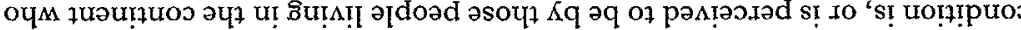

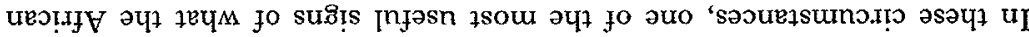

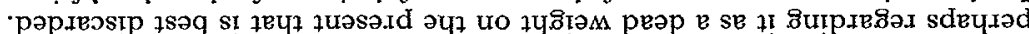

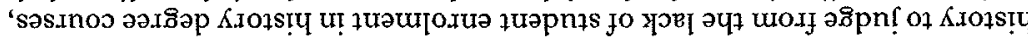

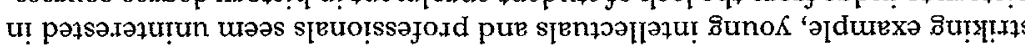

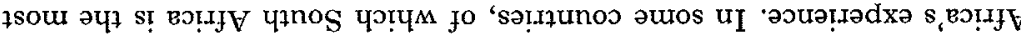

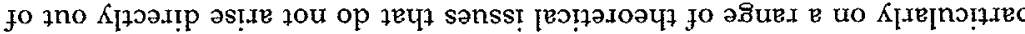

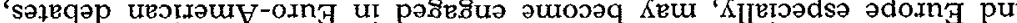

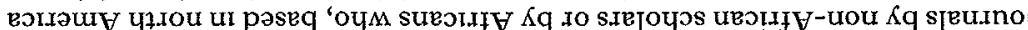

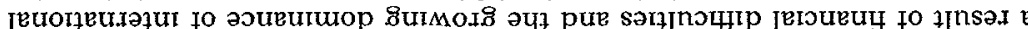

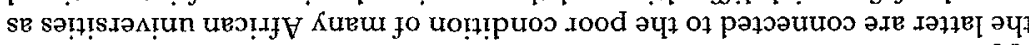

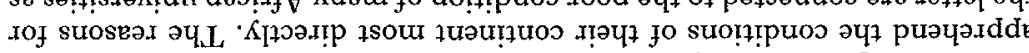

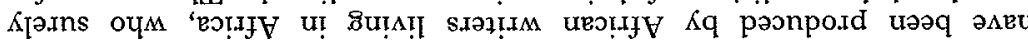

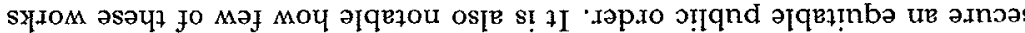

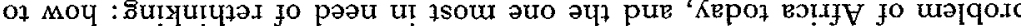
8uाü :

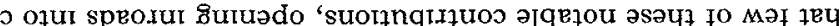

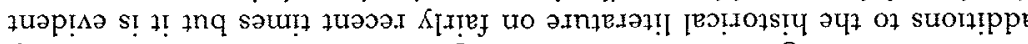
Кчр.

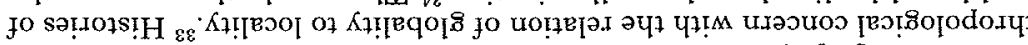

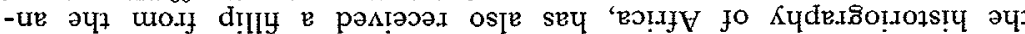

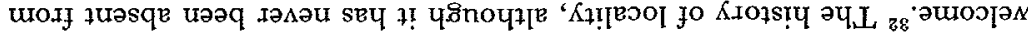

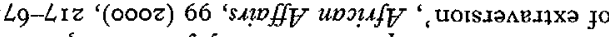

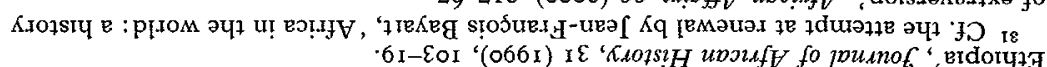

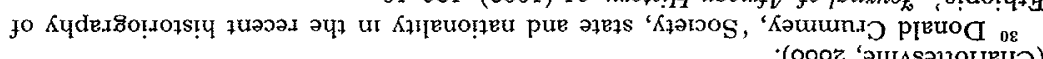

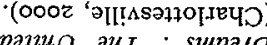

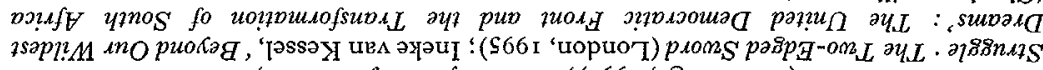

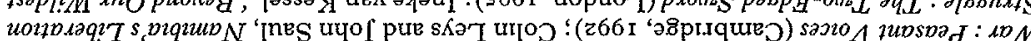

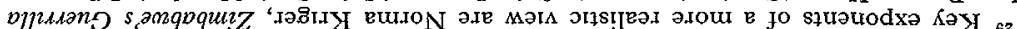

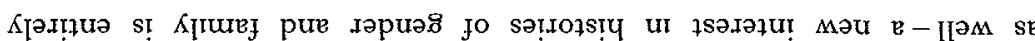

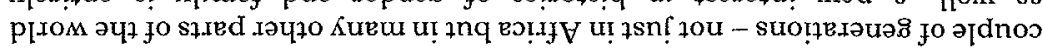

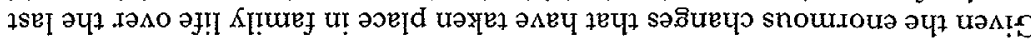

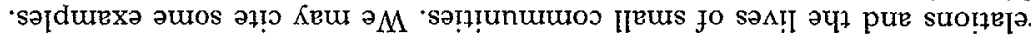

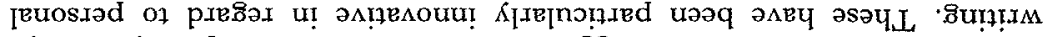

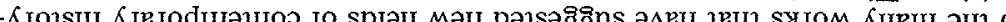

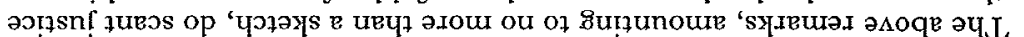

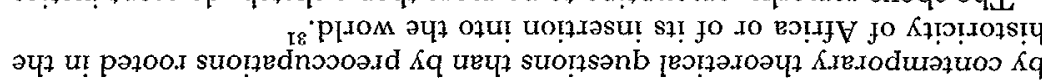

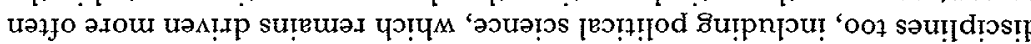

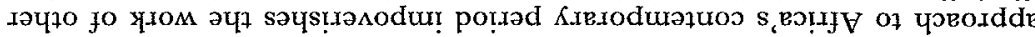

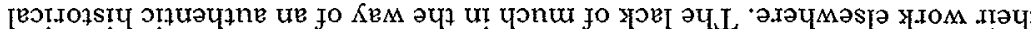
כ0ए

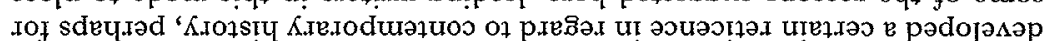

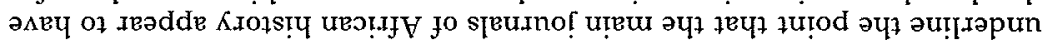

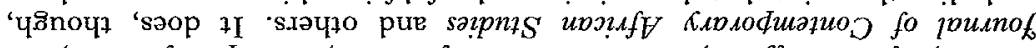

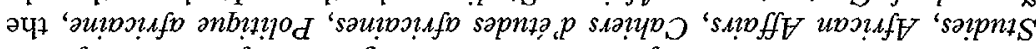

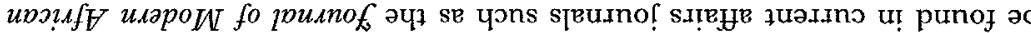
OI оs

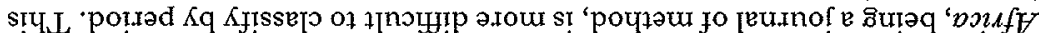

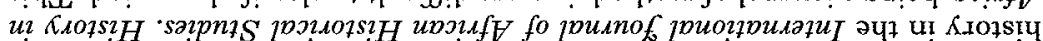

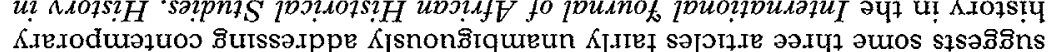

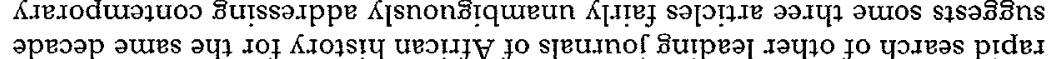

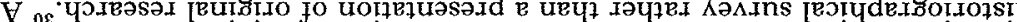

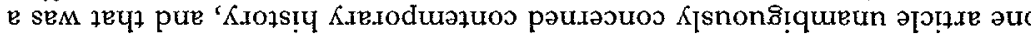

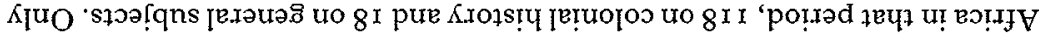

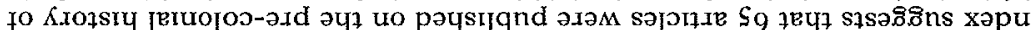

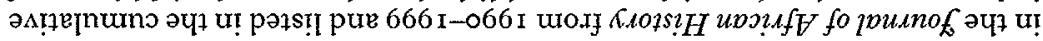

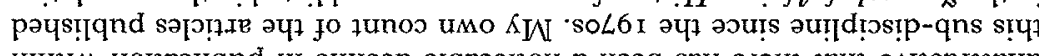
u!ч!!M uo!ฺ

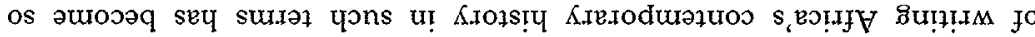

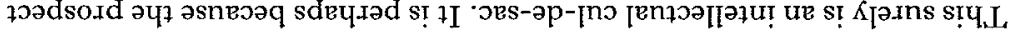

spuny yo pay ur suprie?tupurn

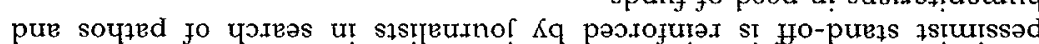

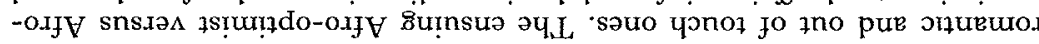
łnq 'słs!um

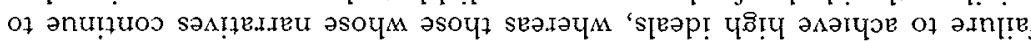

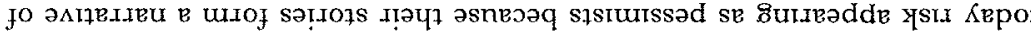

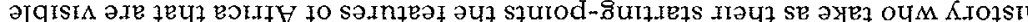

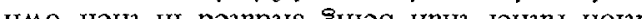




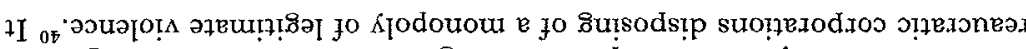

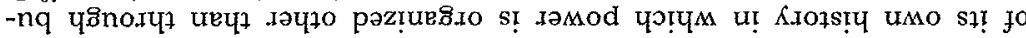

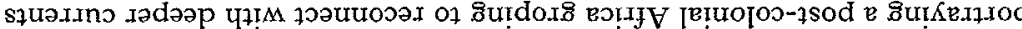

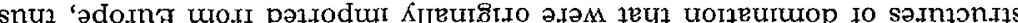
07 tiugns 01 stroteptindod

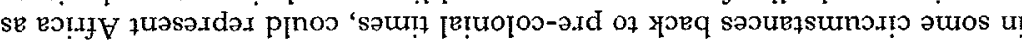

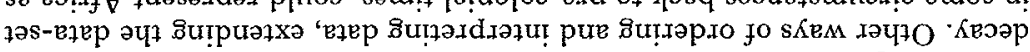

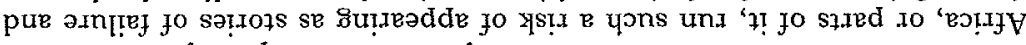

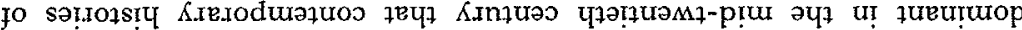

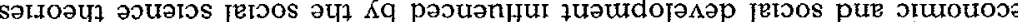

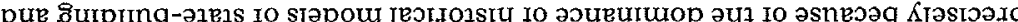

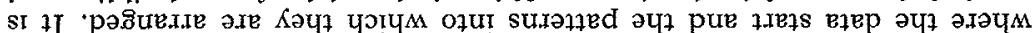

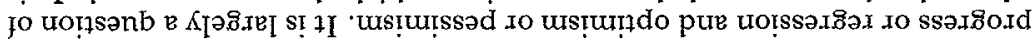

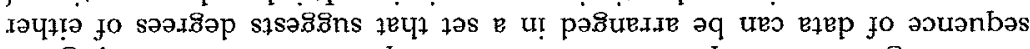

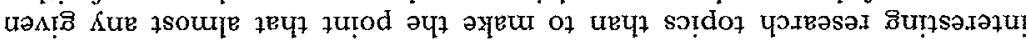

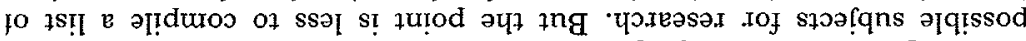

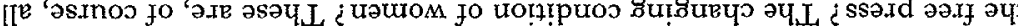

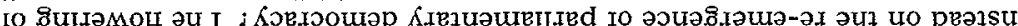
10 8u

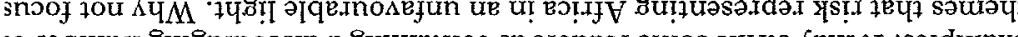

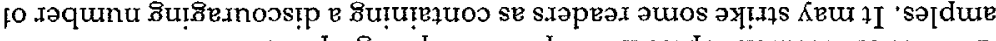

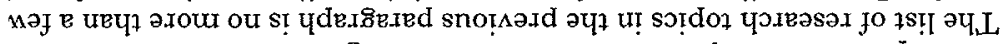

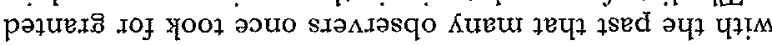

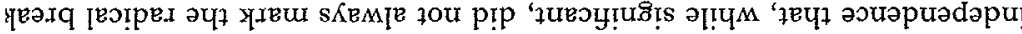

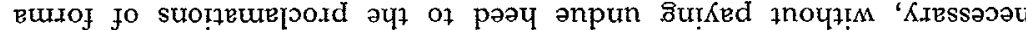

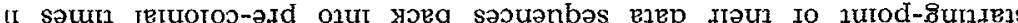

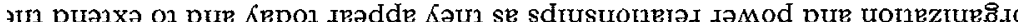

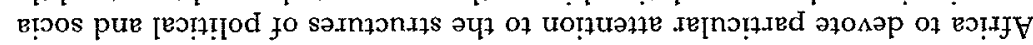

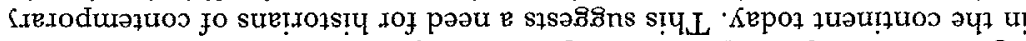

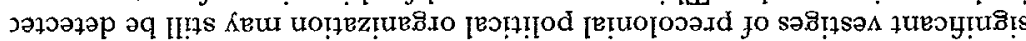

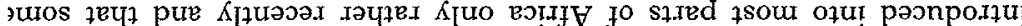

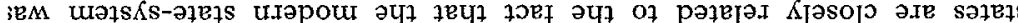

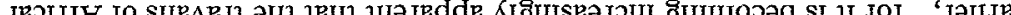
10 s

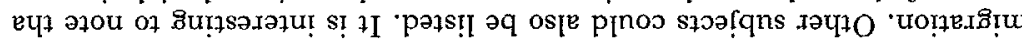

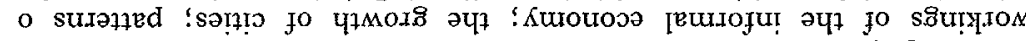

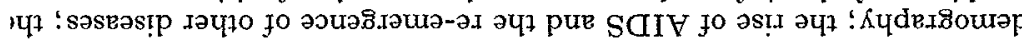

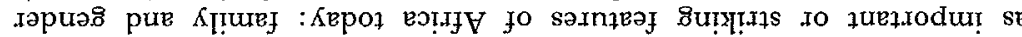

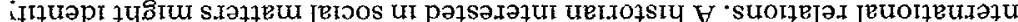

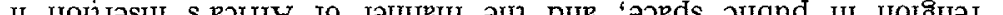
(1)

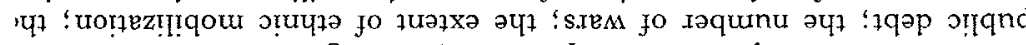

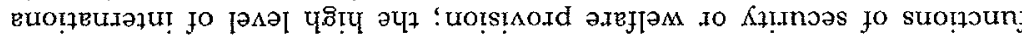

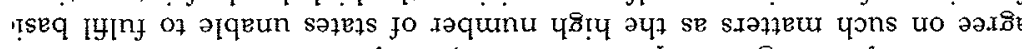

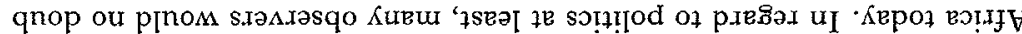

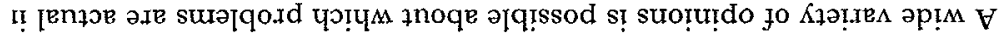

I VDIYAV XYYYOANGINOO HO SAIYOXSIH DNILIYM

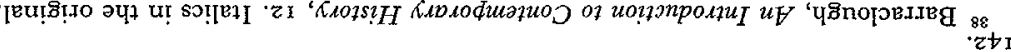
(z661) $+\varepsilon$ " CAO7st

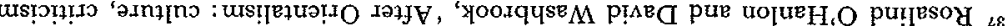

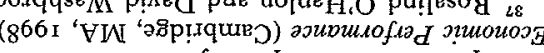

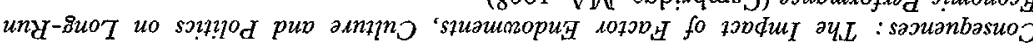

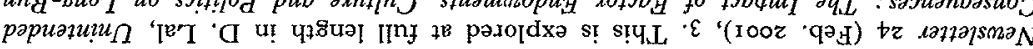

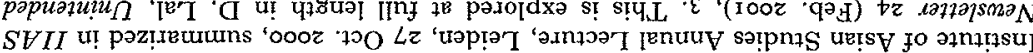

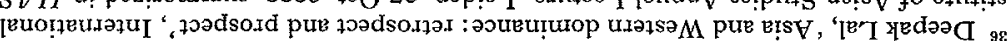

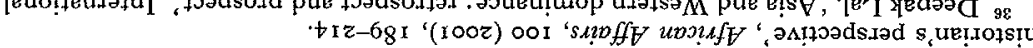

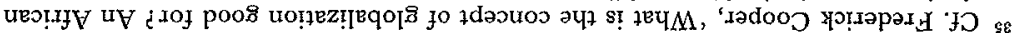

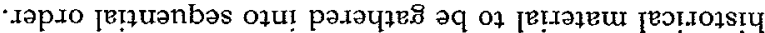

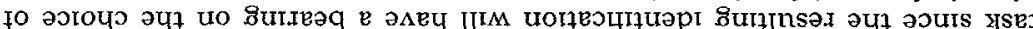

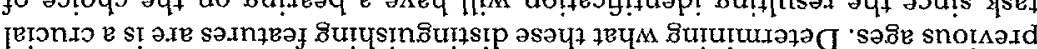

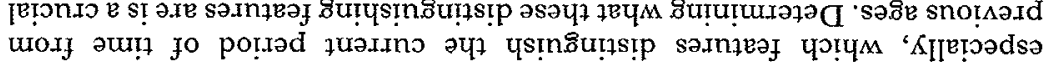

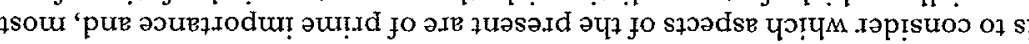

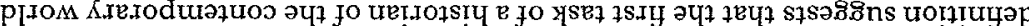

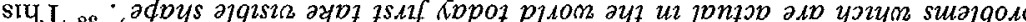

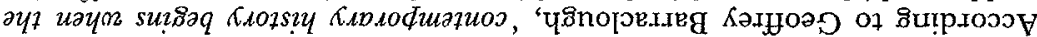

SAMGHX DNIDUANH

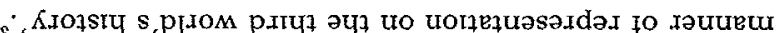

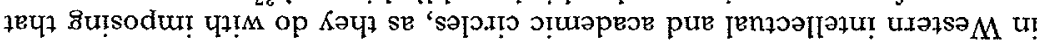

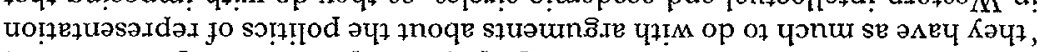

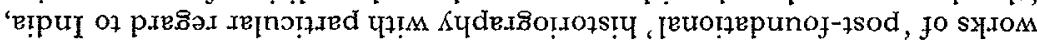

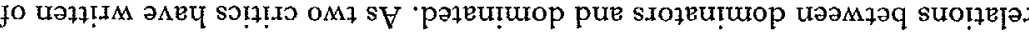

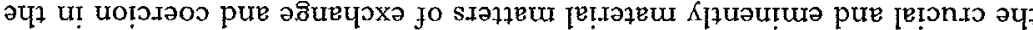

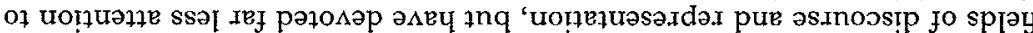

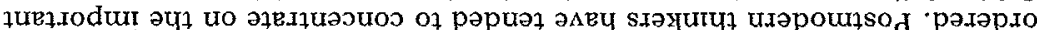

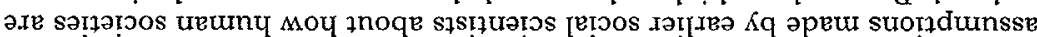

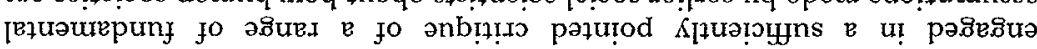

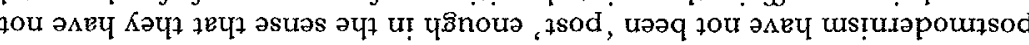

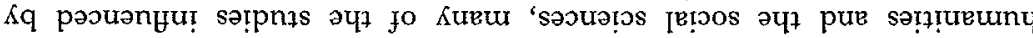

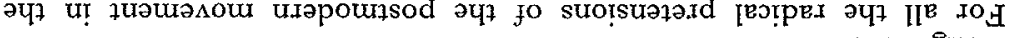

$$
\text { Uomeontisanu! }
$$

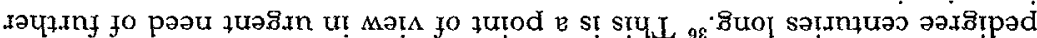

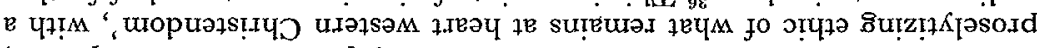

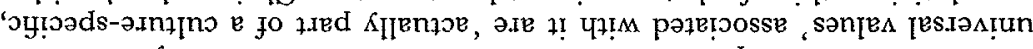

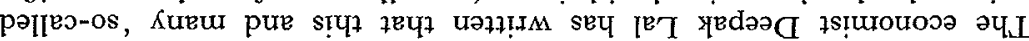
("uoifdurnsse uouruoo e azl.

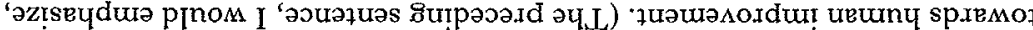

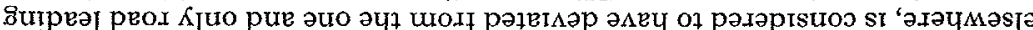

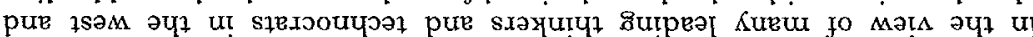
‘วłnox s!

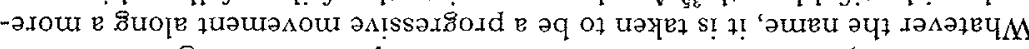

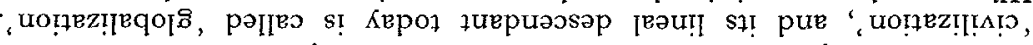
Se eJux

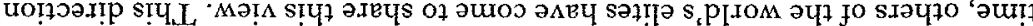

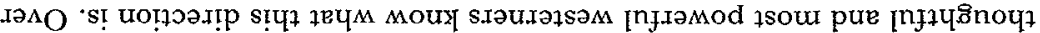




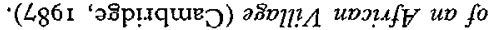
"?pน7.

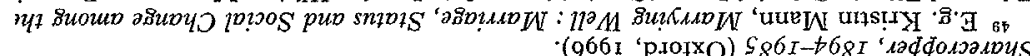

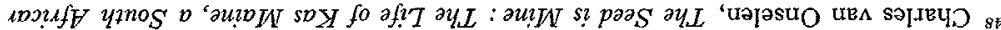

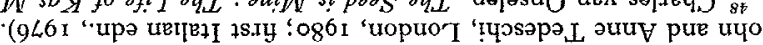

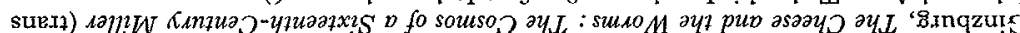

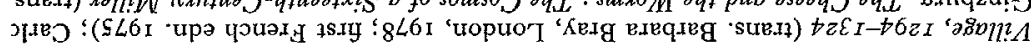

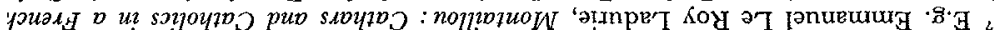
'I I-OI '(666r 'pIOjxo) $48-986$

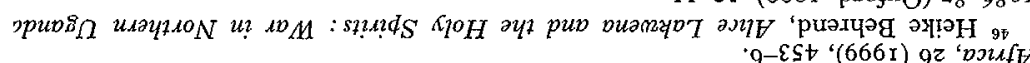

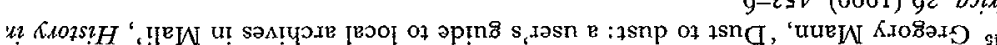

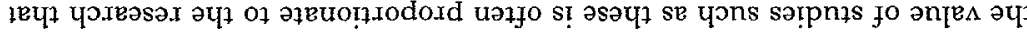

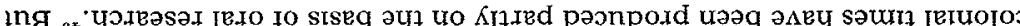
प1

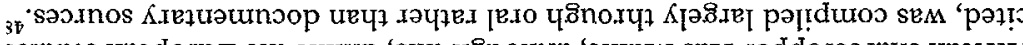

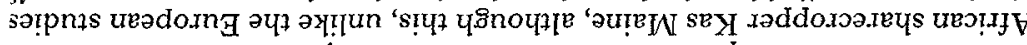

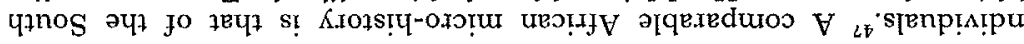

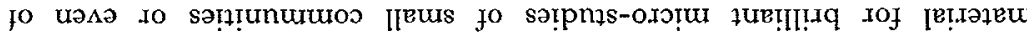

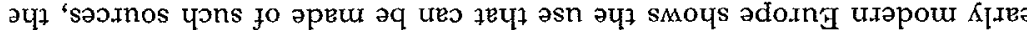
pur fR

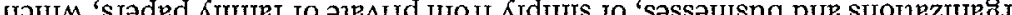

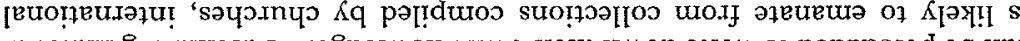

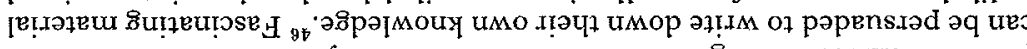

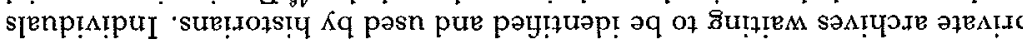

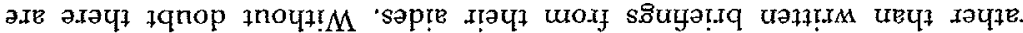

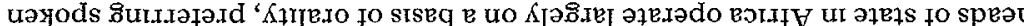

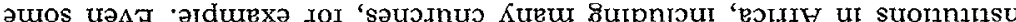

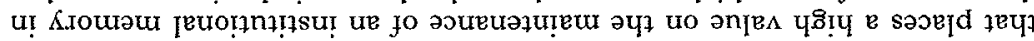

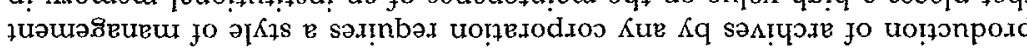

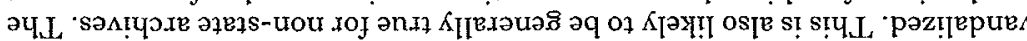

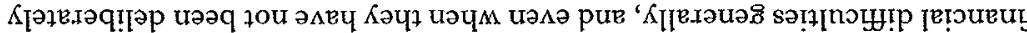

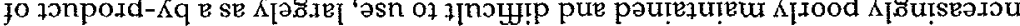

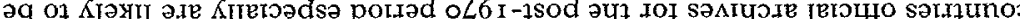

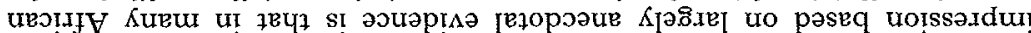

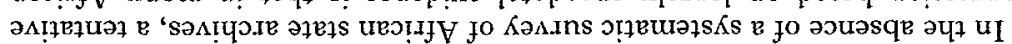

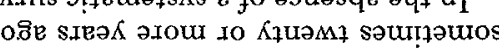

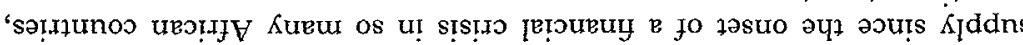
ұ. Чр!Ч

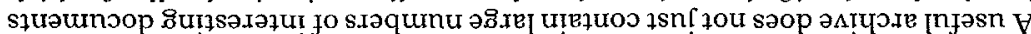

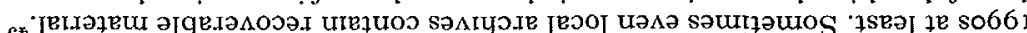

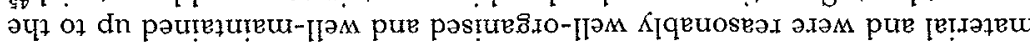

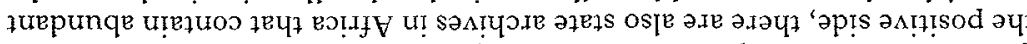

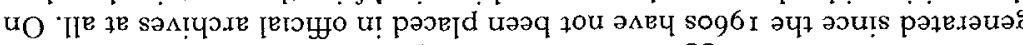

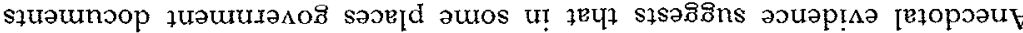

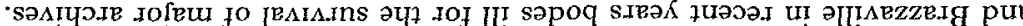

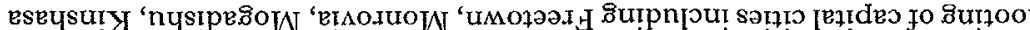

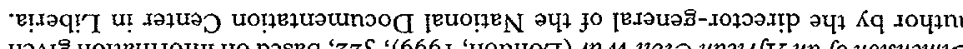

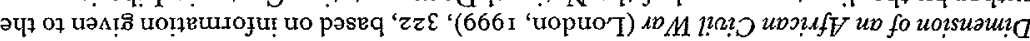
snors?

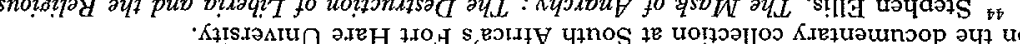

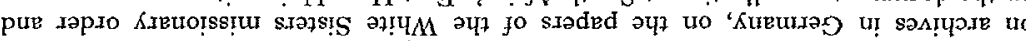

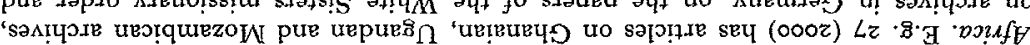

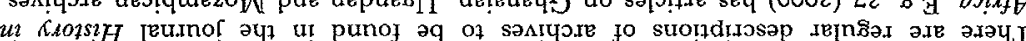

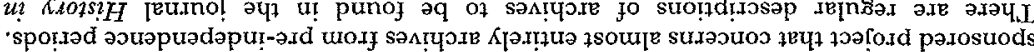

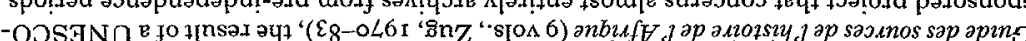

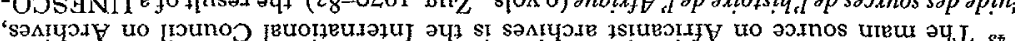

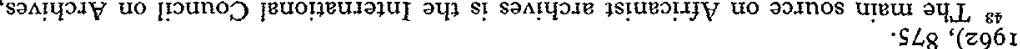

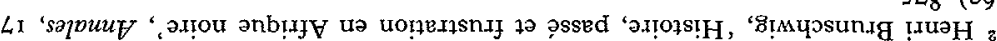

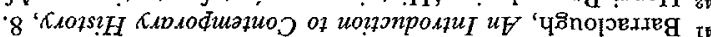

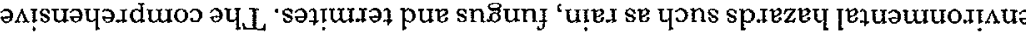
uroxf I0 -

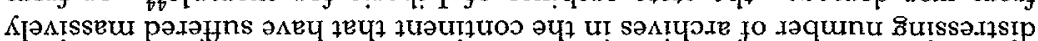

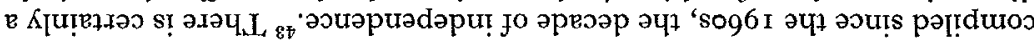

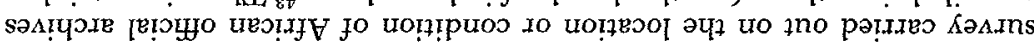

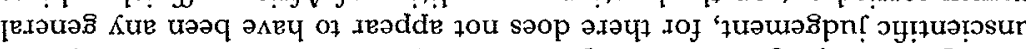

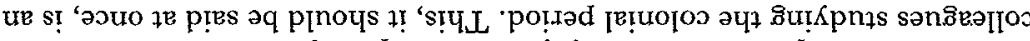

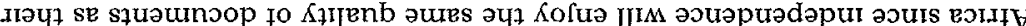

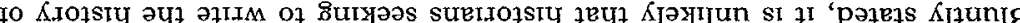
'sIR

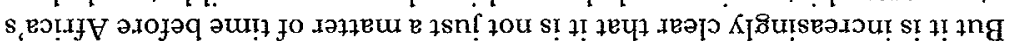

- sәn!y

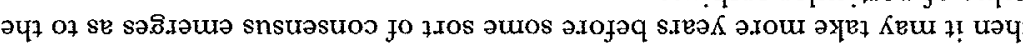

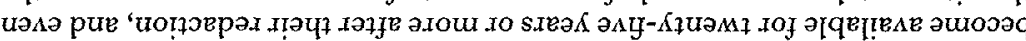

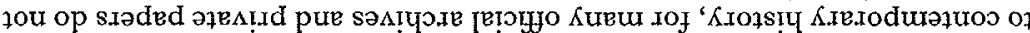

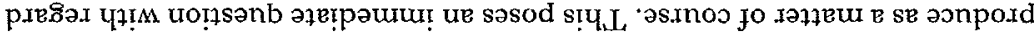

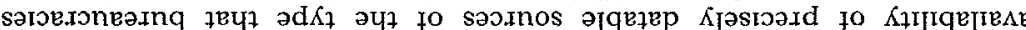

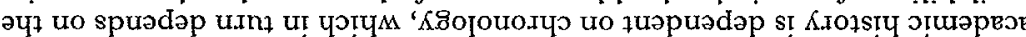

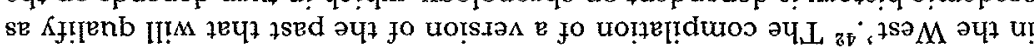

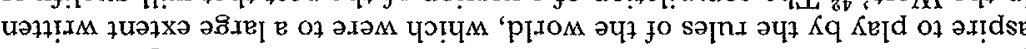

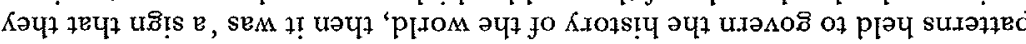

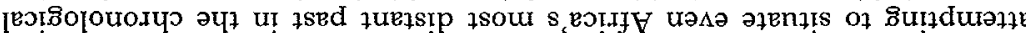

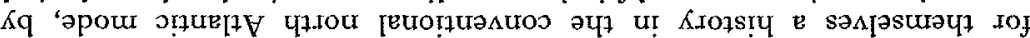

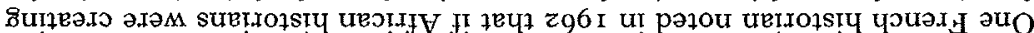
- $\mathrm{K}$.m

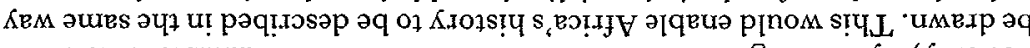

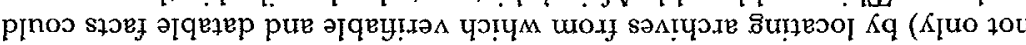

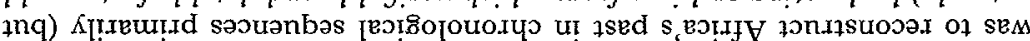

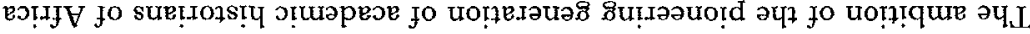

Saวunos

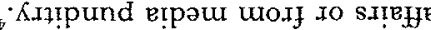

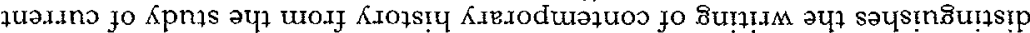

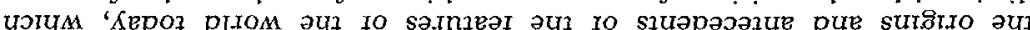

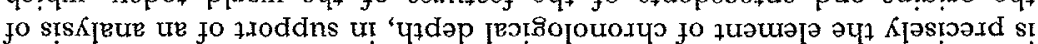




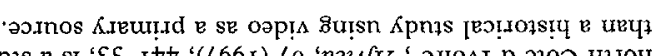

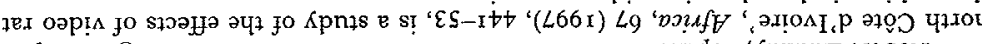

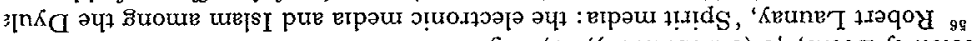

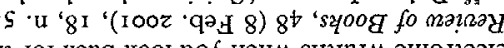

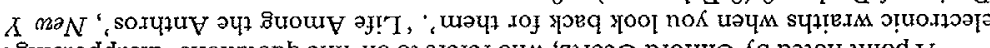

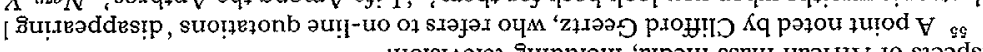

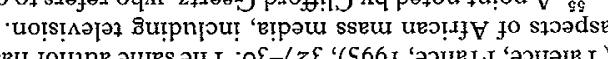

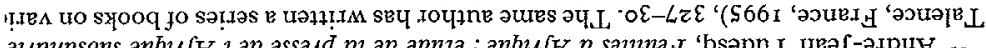

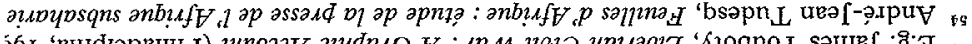

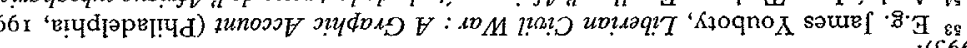

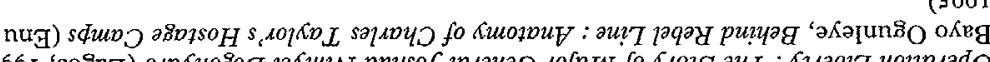

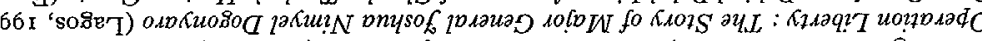

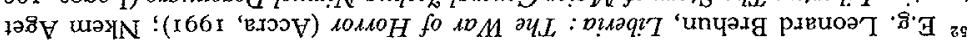

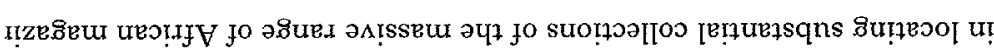

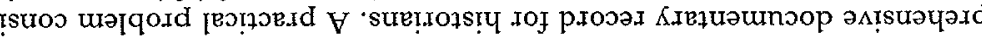

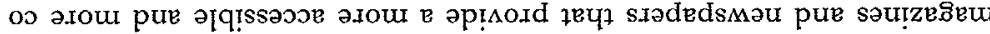

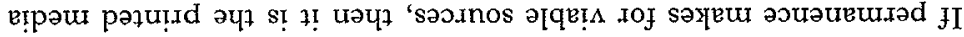

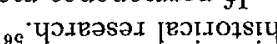

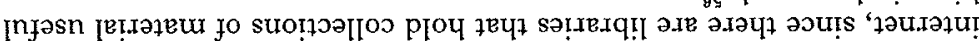

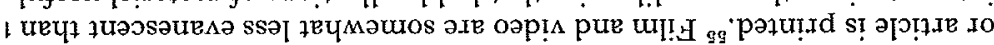

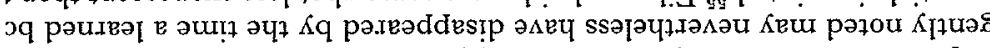

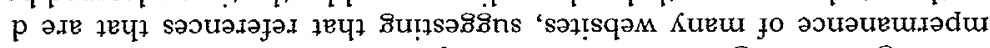

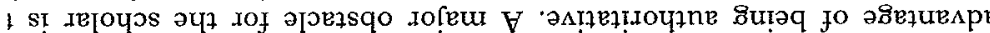

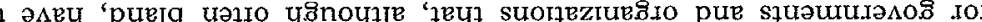

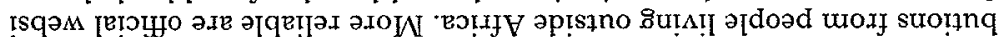

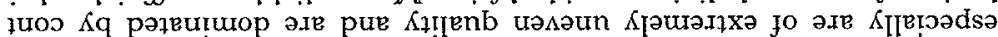

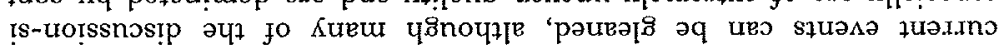

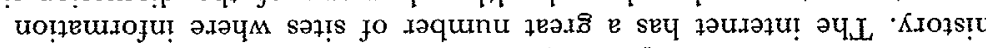

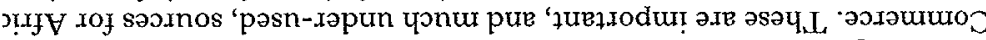

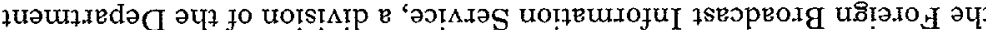

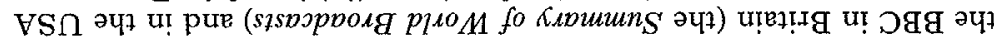

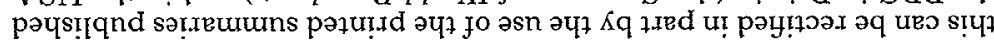

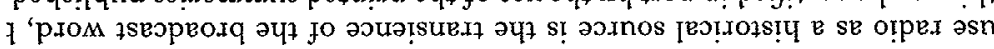

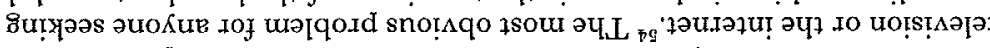
paux pazu!nd op ueчt suro!.

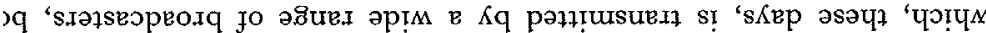

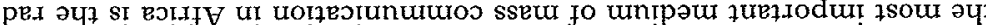

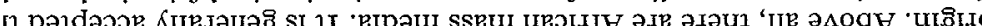
KInuno ג.7и

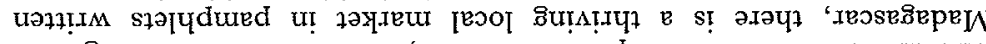

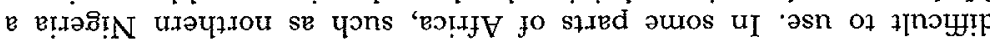

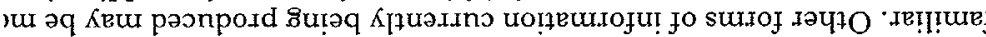
\}ul.nnssea. puy IIIM sue!.

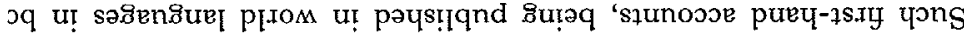

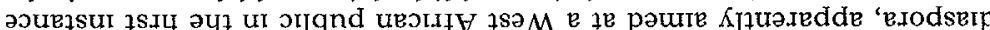
.

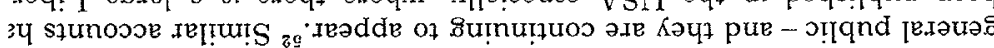

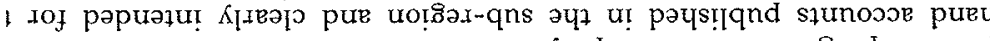

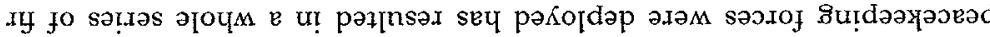

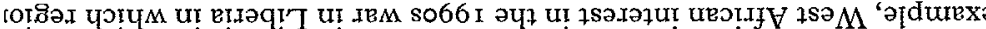

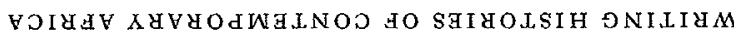

(

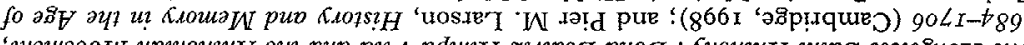

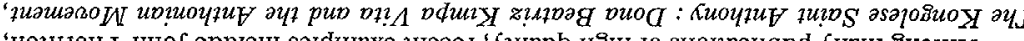

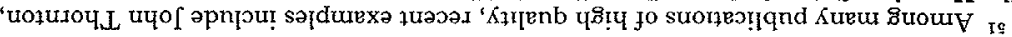
X-1:A "(S66I 'tropuót)

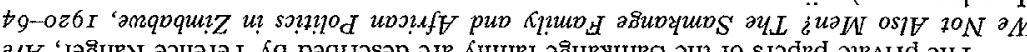
ә

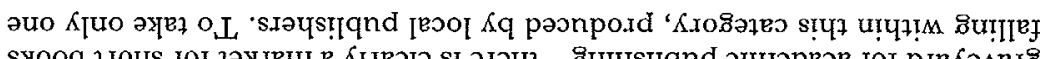

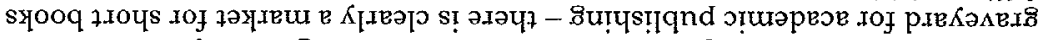

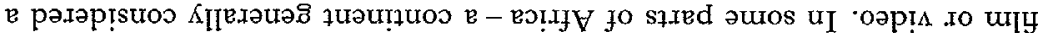

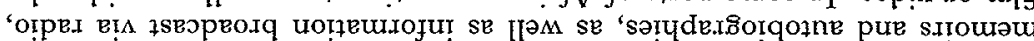

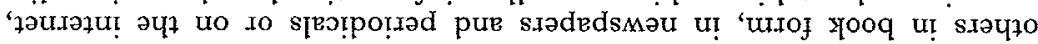

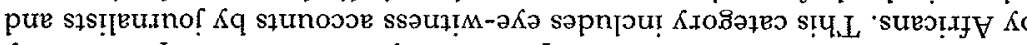

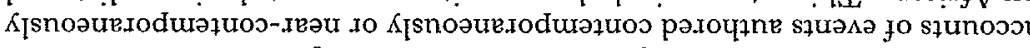

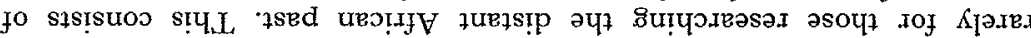

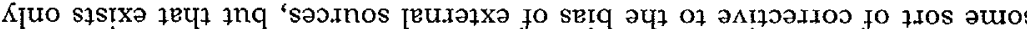

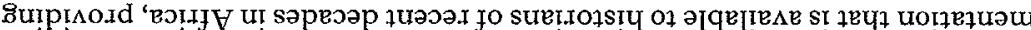

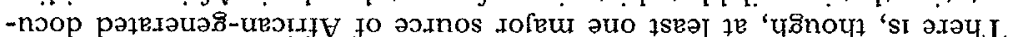

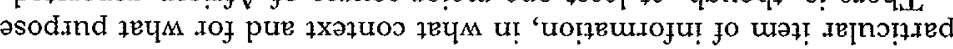

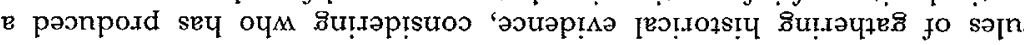

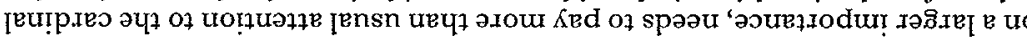

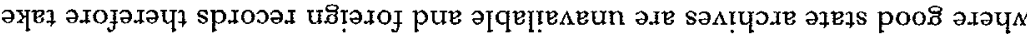

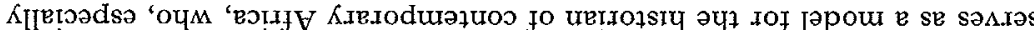

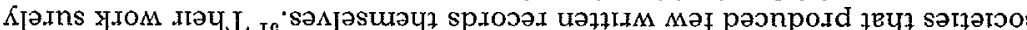

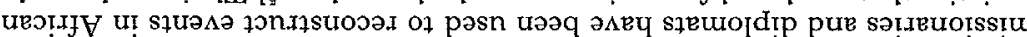

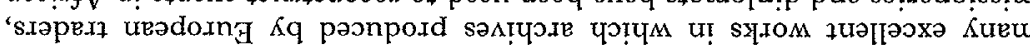

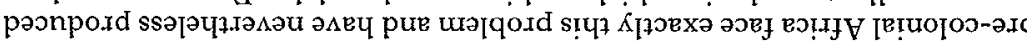

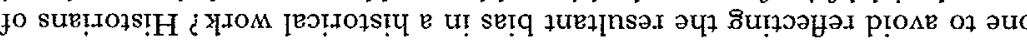

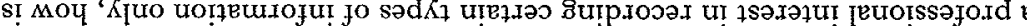

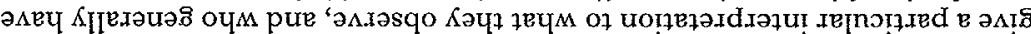

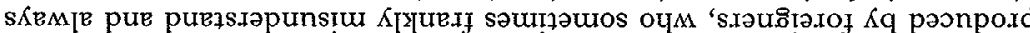

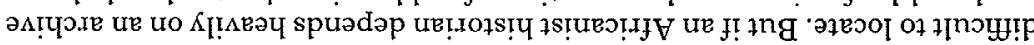
Кำ ' К К[

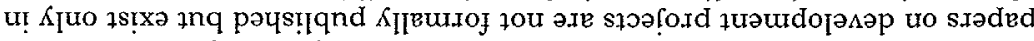

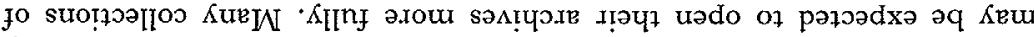

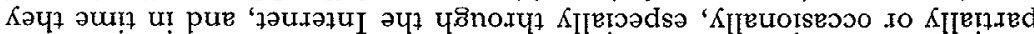

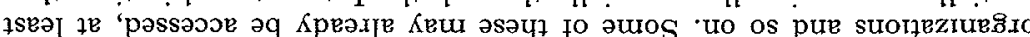

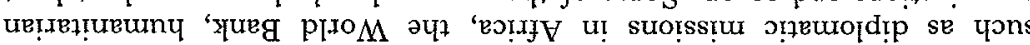

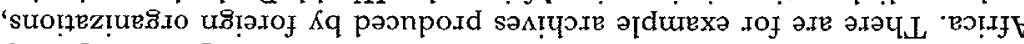

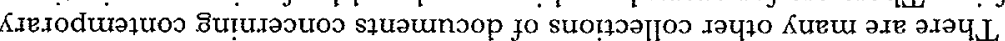

'Karoos xapim әчt znoqe jer.jajeu

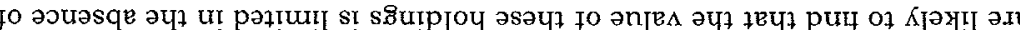

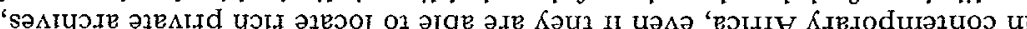

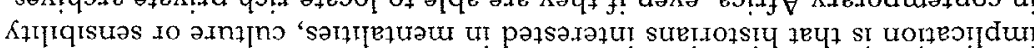

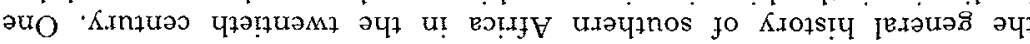

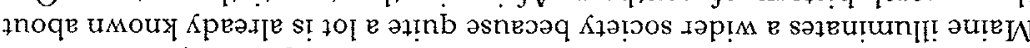

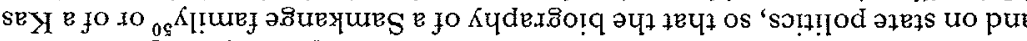

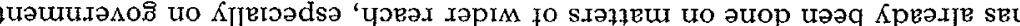




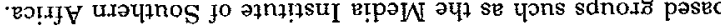

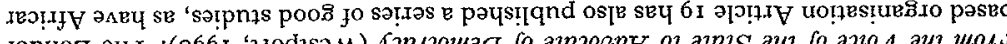

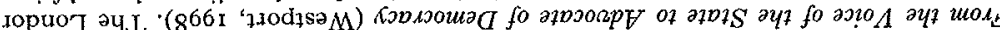

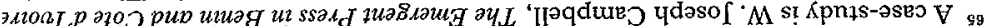

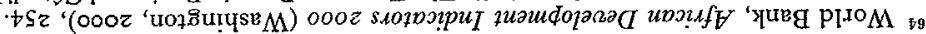

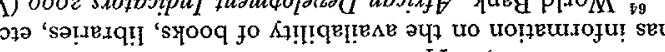

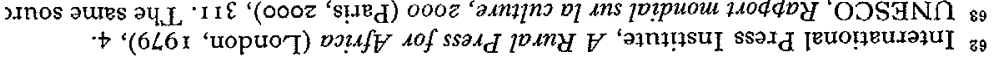

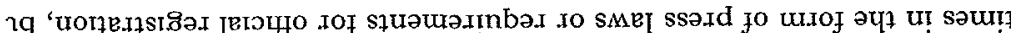

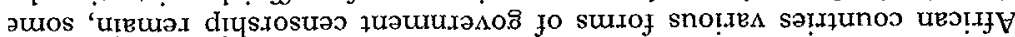

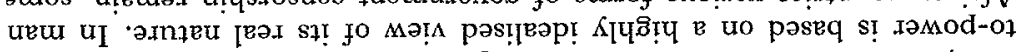

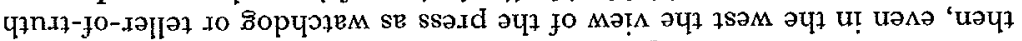

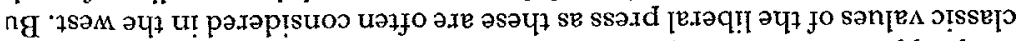

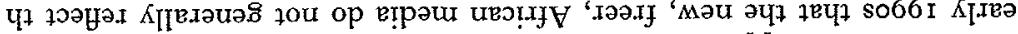

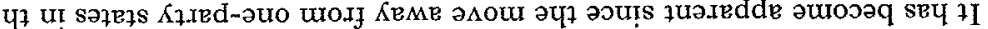

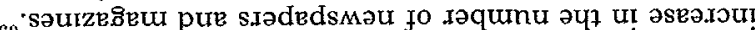

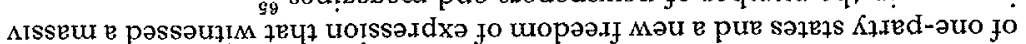

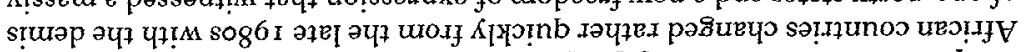

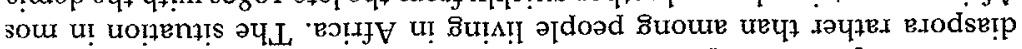

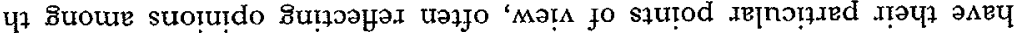

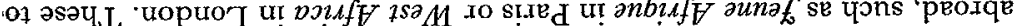

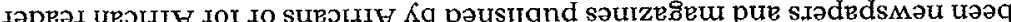
1

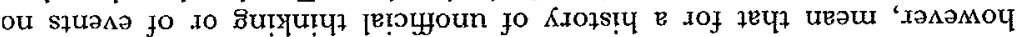

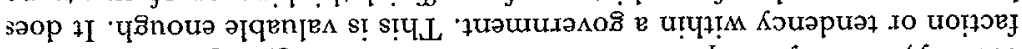

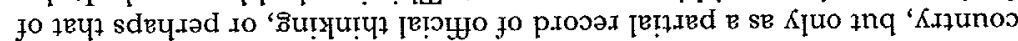

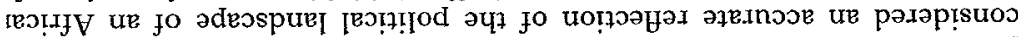

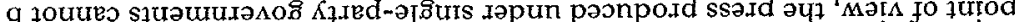

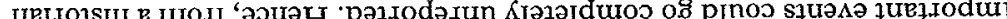

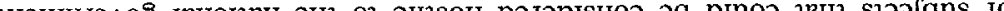

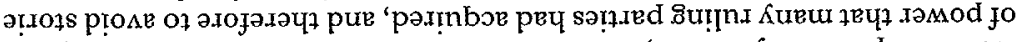

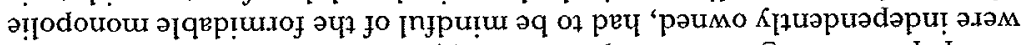

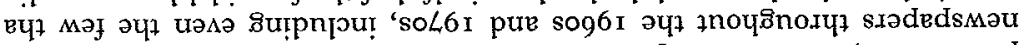

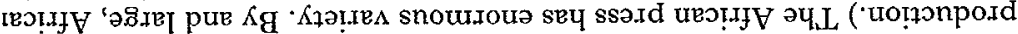

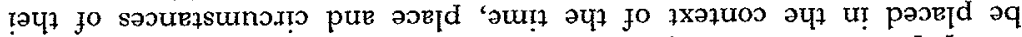

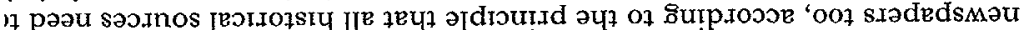

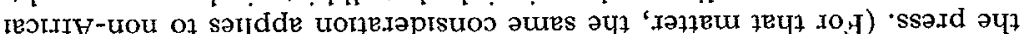

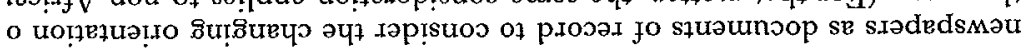

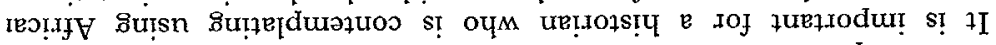

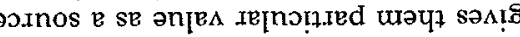

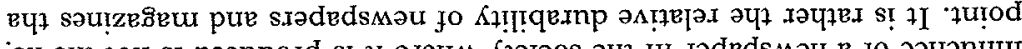

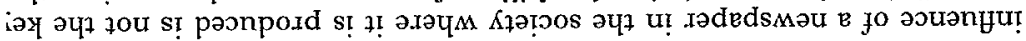

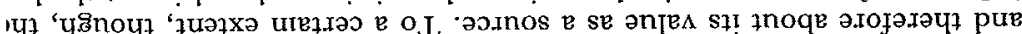

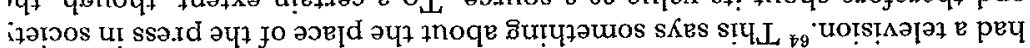

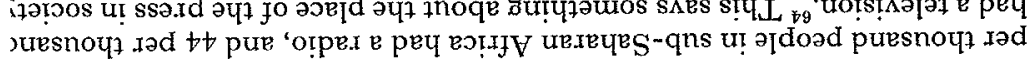

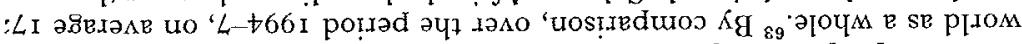

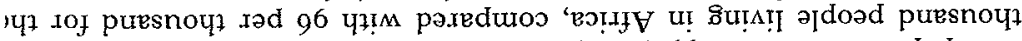

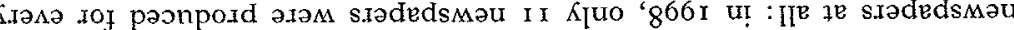

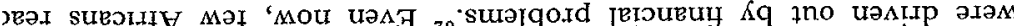

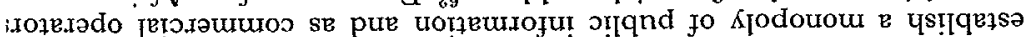

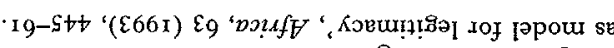

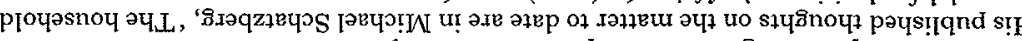

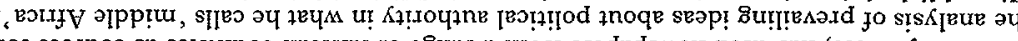
xоł səannos se sa!nu вuвipuI $\mathrm{Kq}$ uo!̣eग!

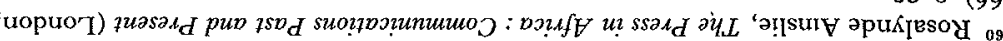

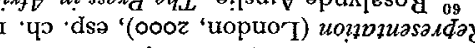

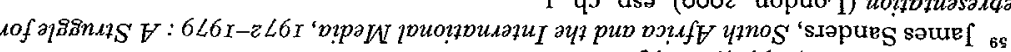
- $26-09$ '(066 ' 'YIOX MəN) Kio7s?

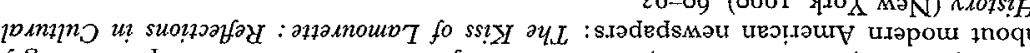

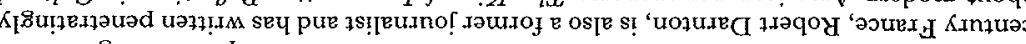

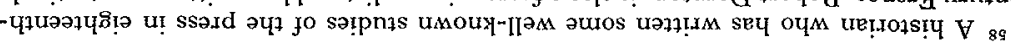
suo!noวก

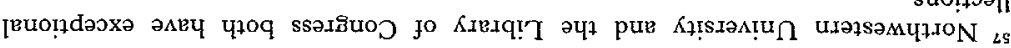

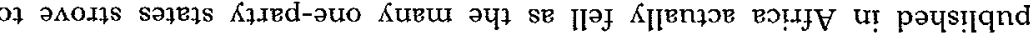

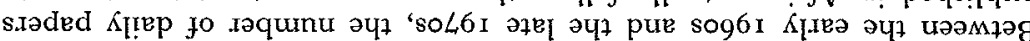

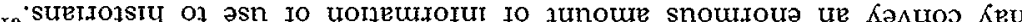
(1)

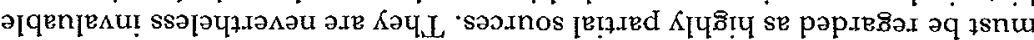
әd $\AA_{1}$ s!

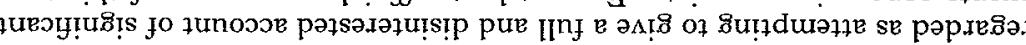

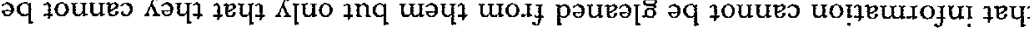

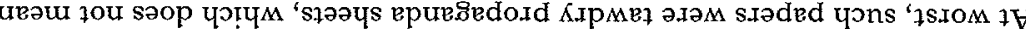

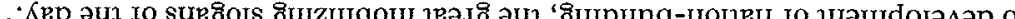

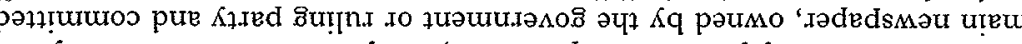
әuо $K$ [

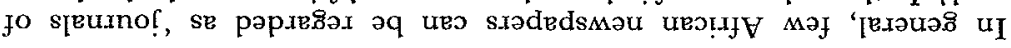

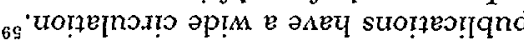

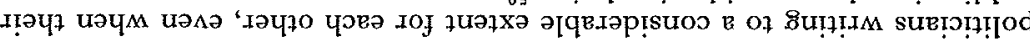

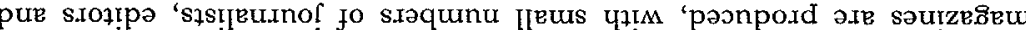

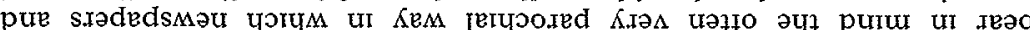

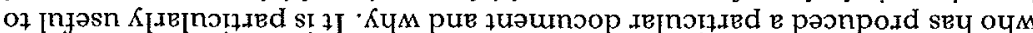

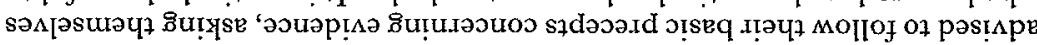

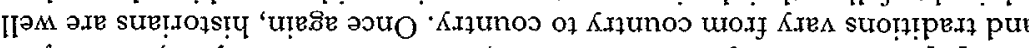

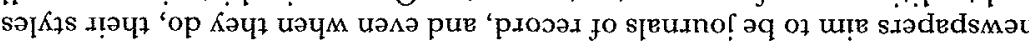

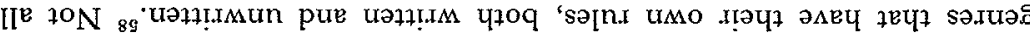

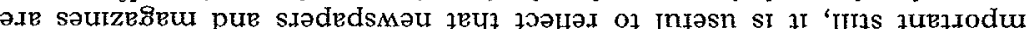

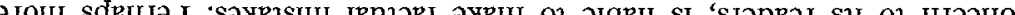
Jo st leul pure pauaddeu sey ley

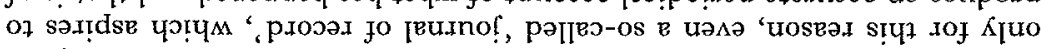

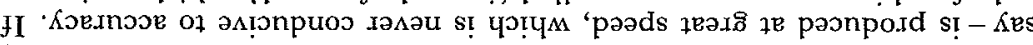

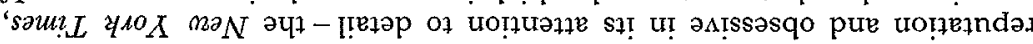

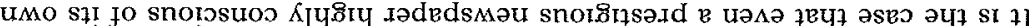

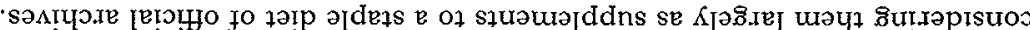
a 07 วұеurn!

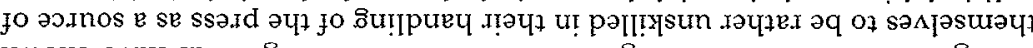

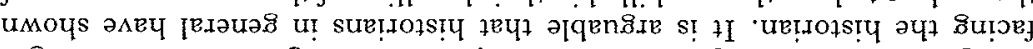

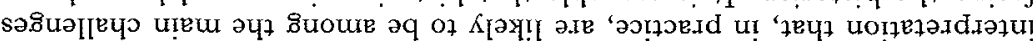

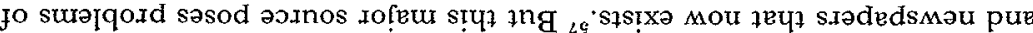

SITTA NGHAGIS 


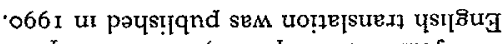

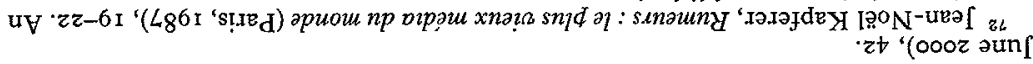

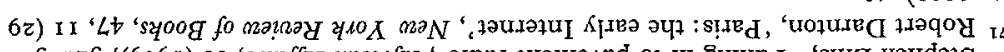

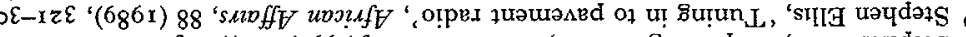

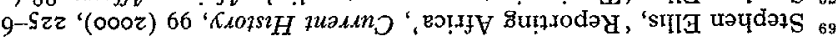

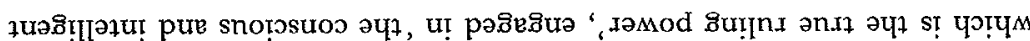

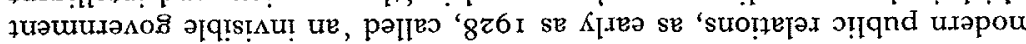

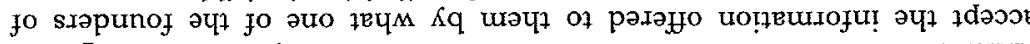

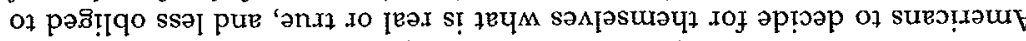

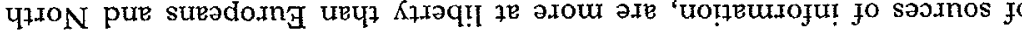

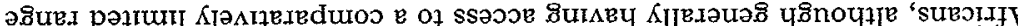
'punos fru '

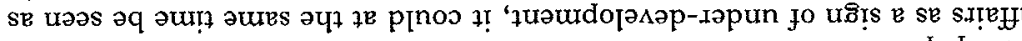

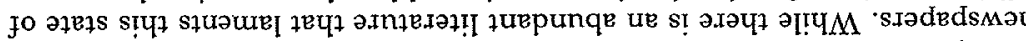

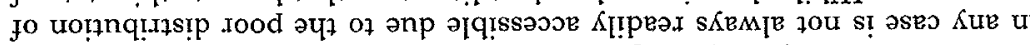
чәтчм 'suonn!

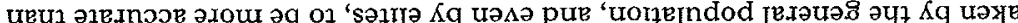

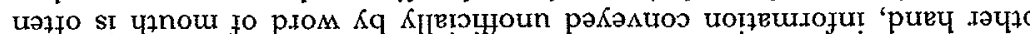

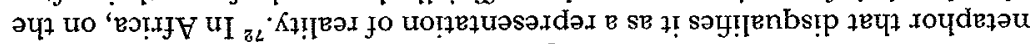

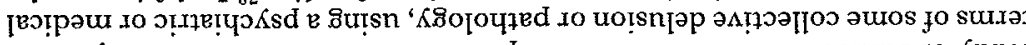

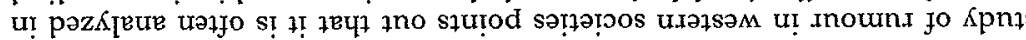

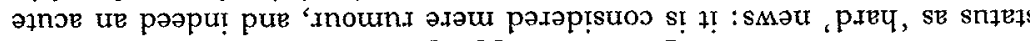

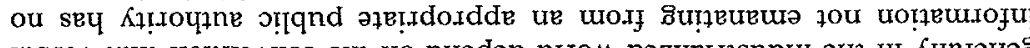

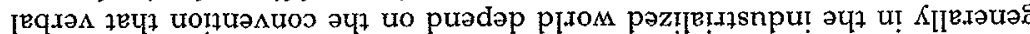

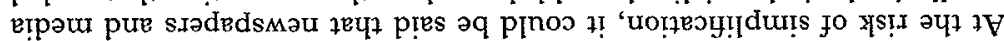
sassвu әч

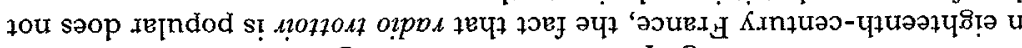
se 'вolIfY uI $\tau_{i}$; uo!̣e

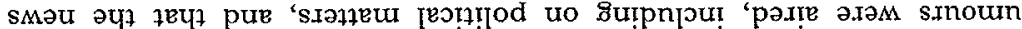

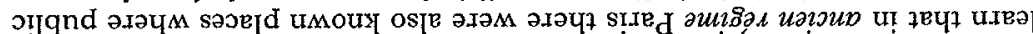

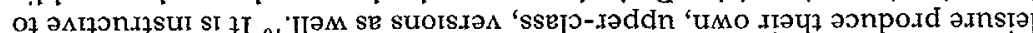

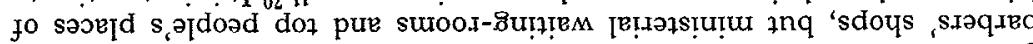

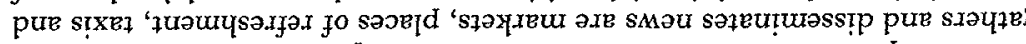

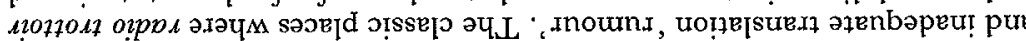

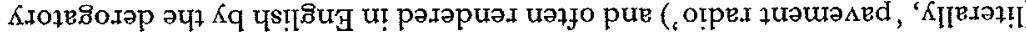

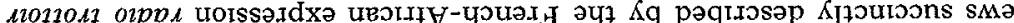
wayods 'T"Poun

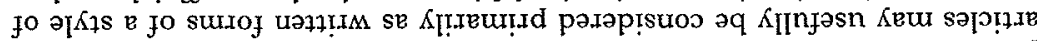

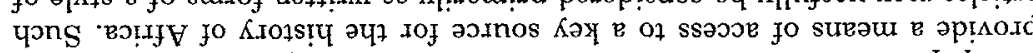

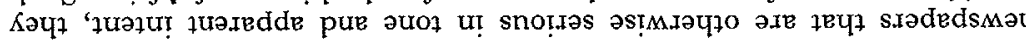

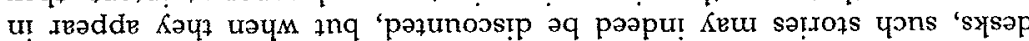

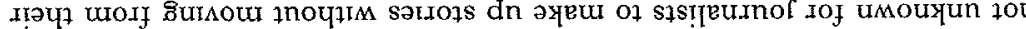

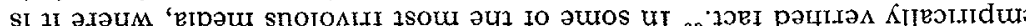
(1)

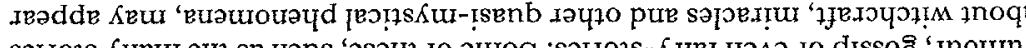

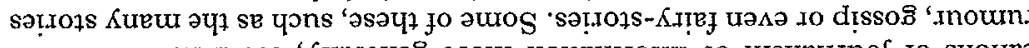

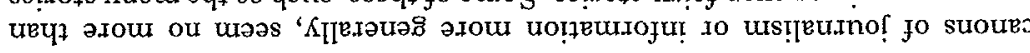

$\angle \cdot(\mathcal{E} 66 \mathrm{r})$

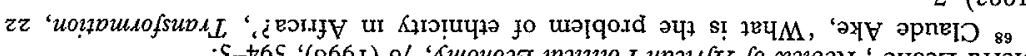

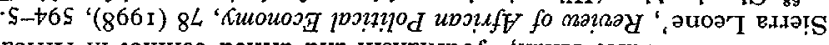

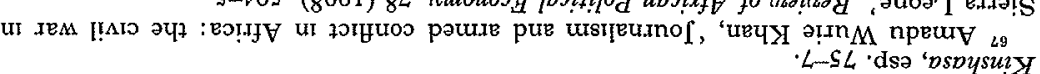

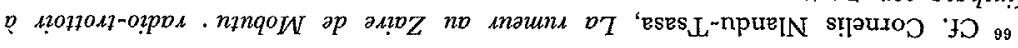

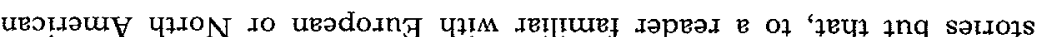

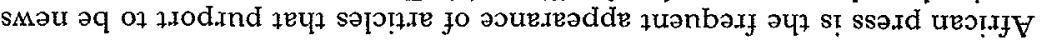

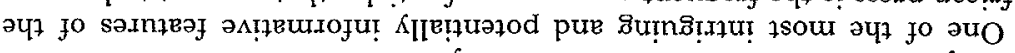

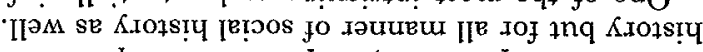
โеว!!!

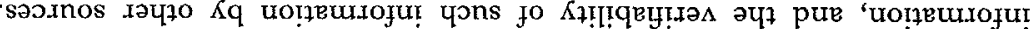

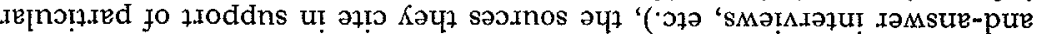

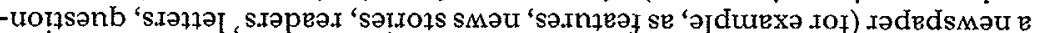

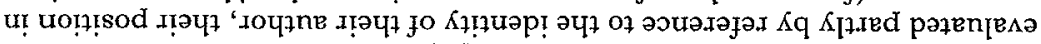

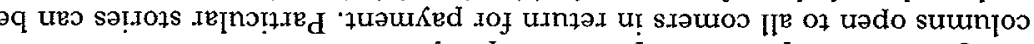

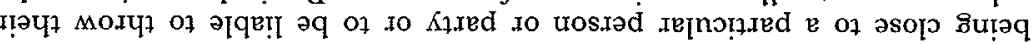
se uмouy әq 7Ч

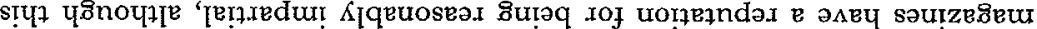

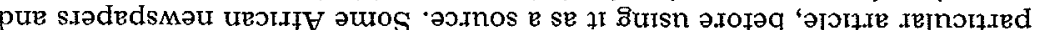

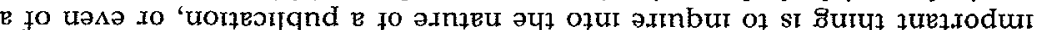
әЧ $L$ ' Kepol eग!

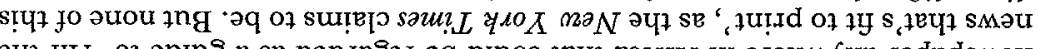

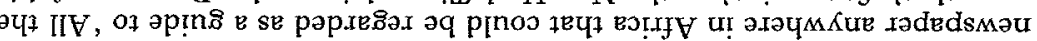

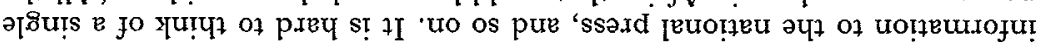

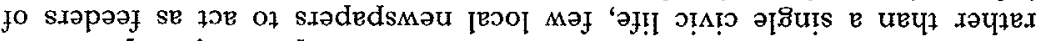

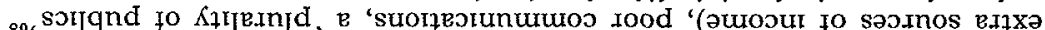

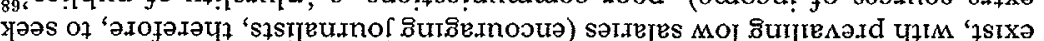

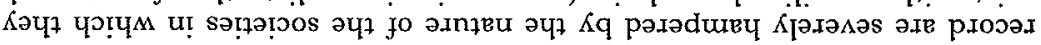

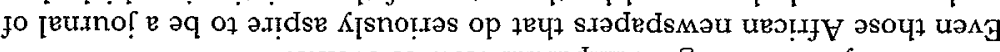

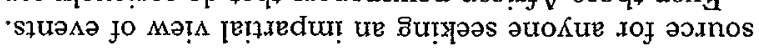

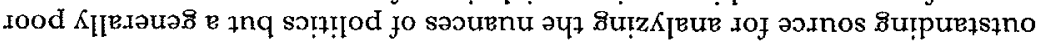

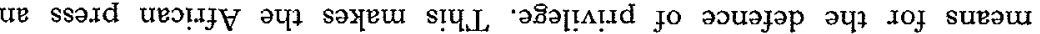

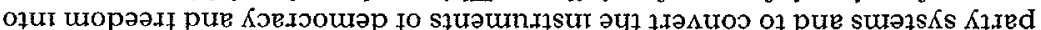

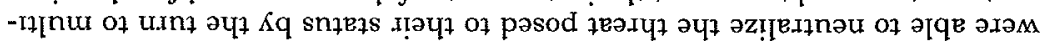

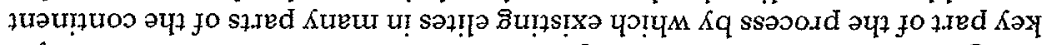

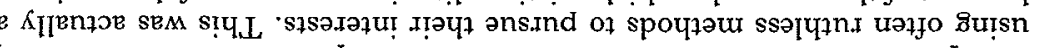

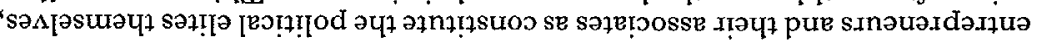

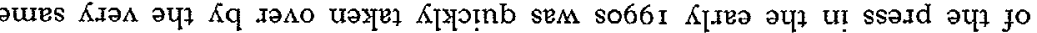

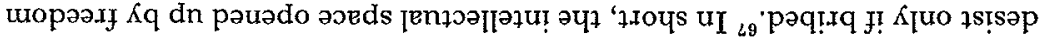

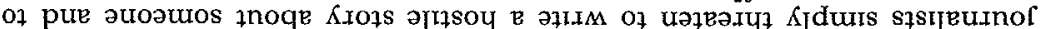

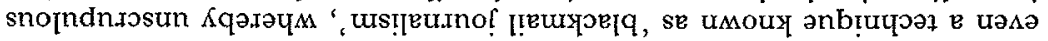

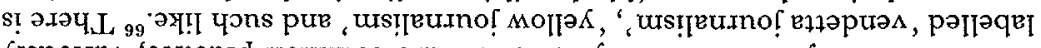

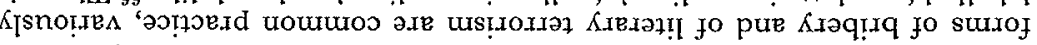

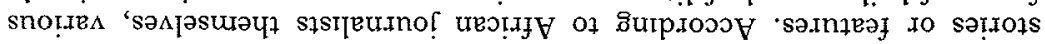

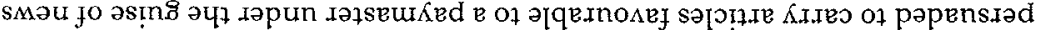

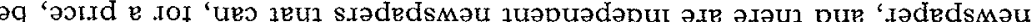

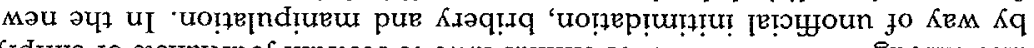

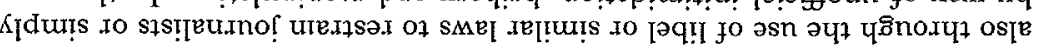




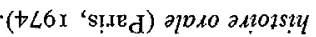

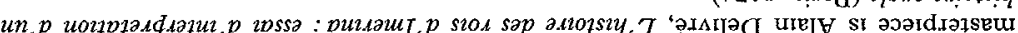

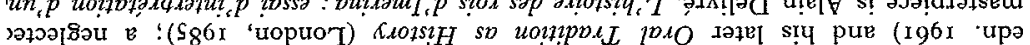

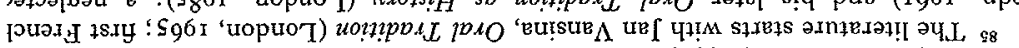

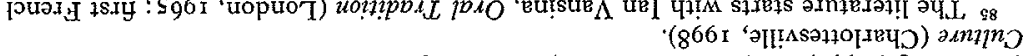

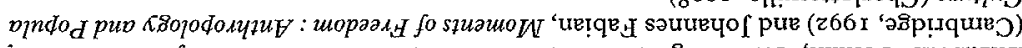

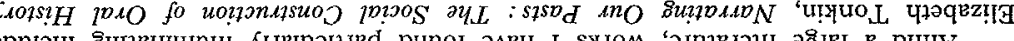
'pn

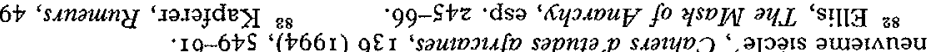
xip ne วuUese әune

( $666 \mathrm{I}$ ' $6-8 \varepsilon$ 'su?

nq 'วnโе

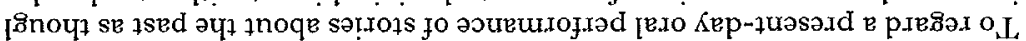

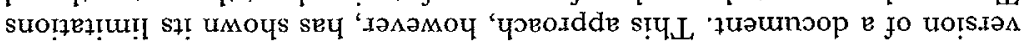

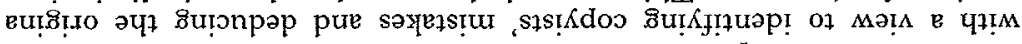

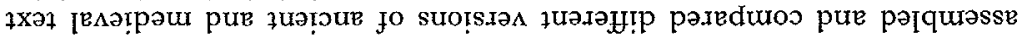

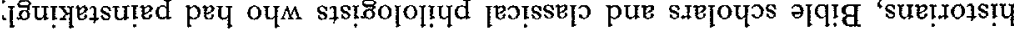

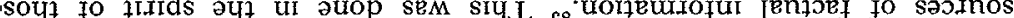
(1)

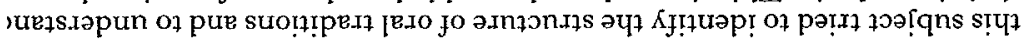

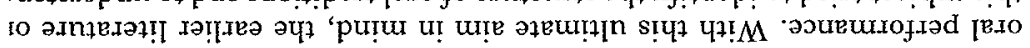

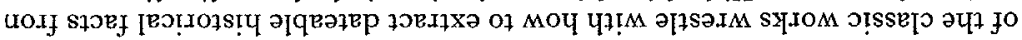

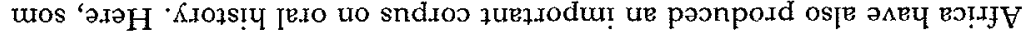

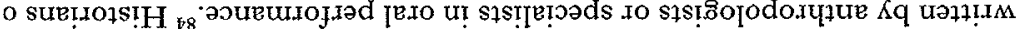

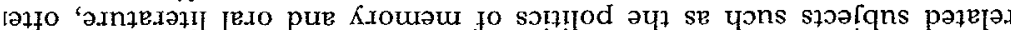

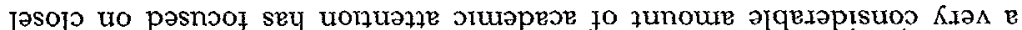

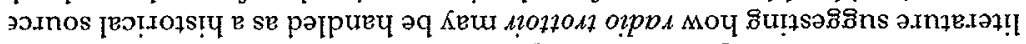

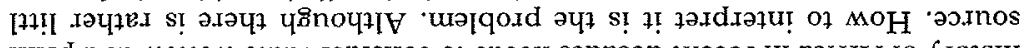

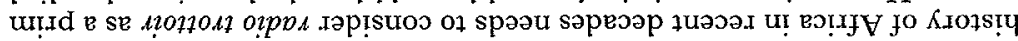

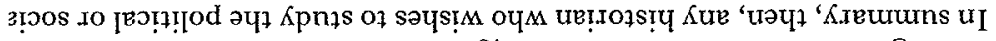

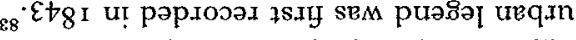

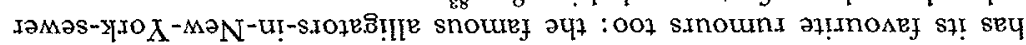

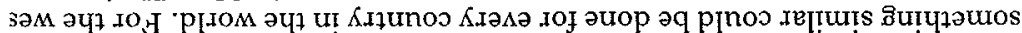
әәрu! pue 'Kı)

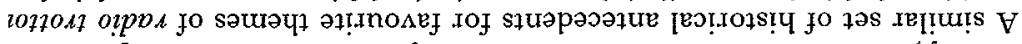

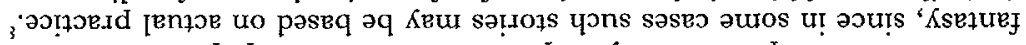

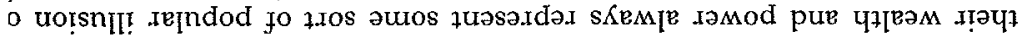

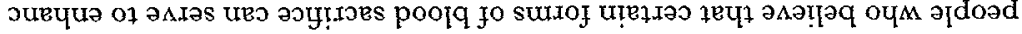

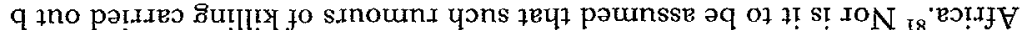

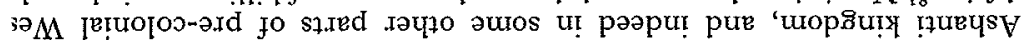

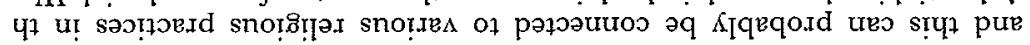

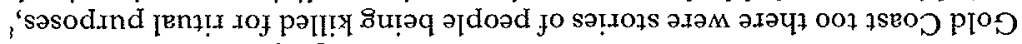

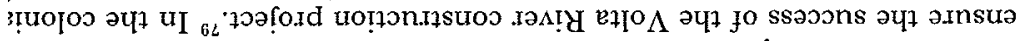

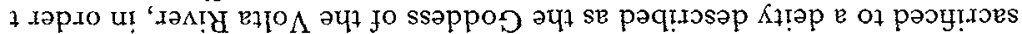

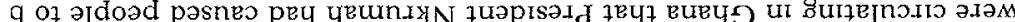

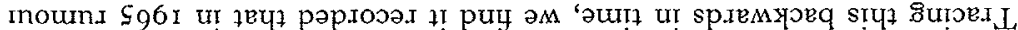

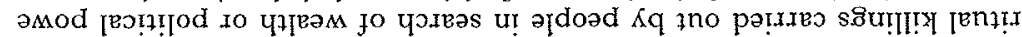

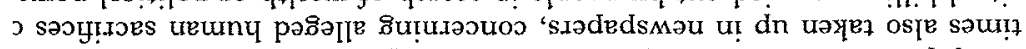

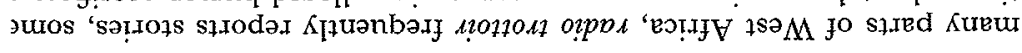

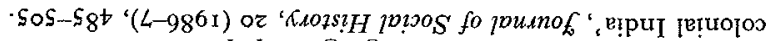

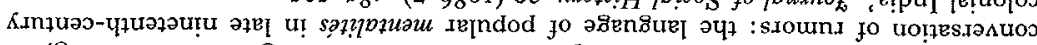

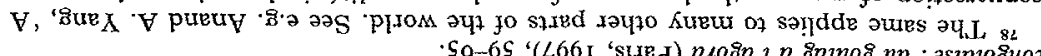

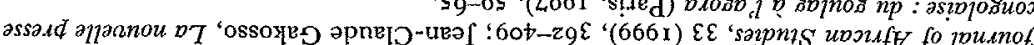

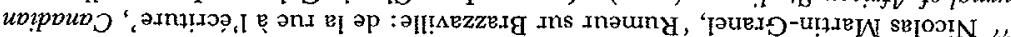

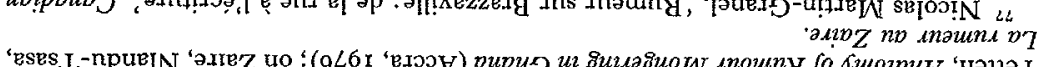

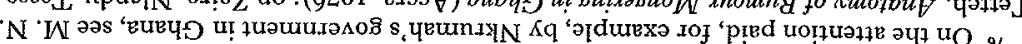

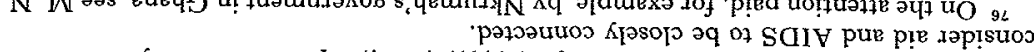

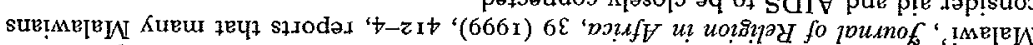

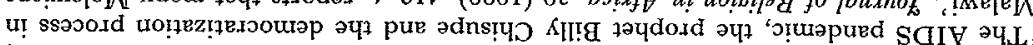

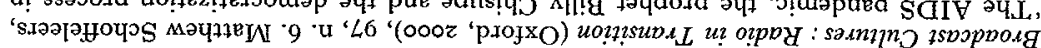
unonffy '('spa) ssium

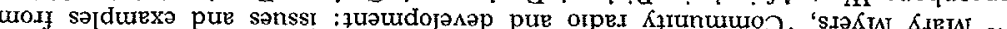

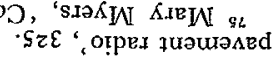

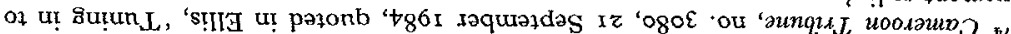

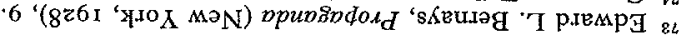

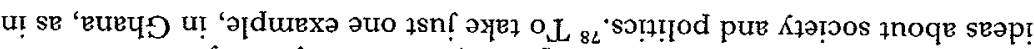

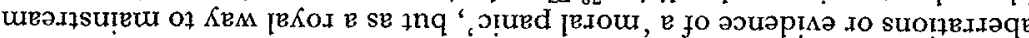

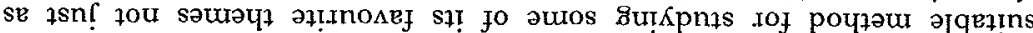

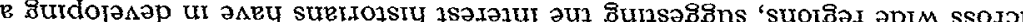

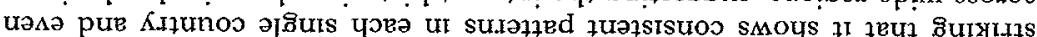

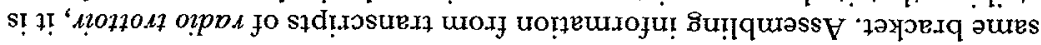

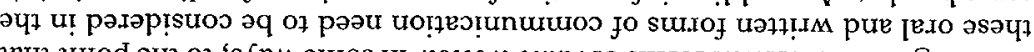

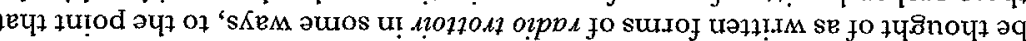

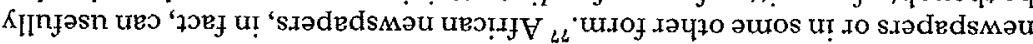

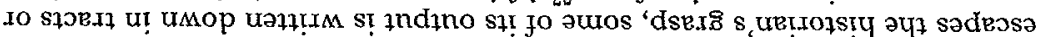

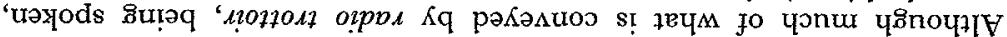

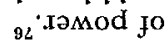

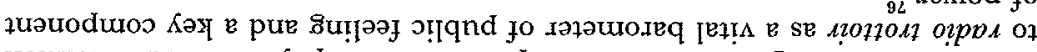

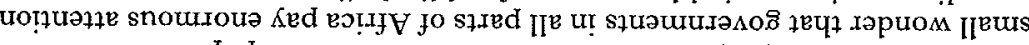

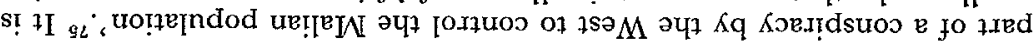

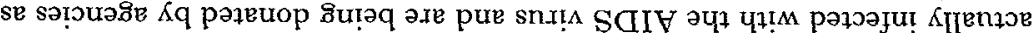

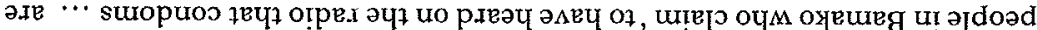
(8)

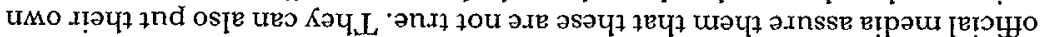

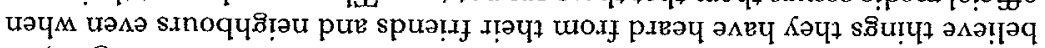

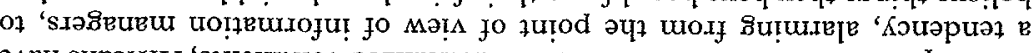

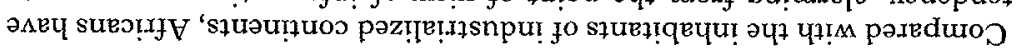

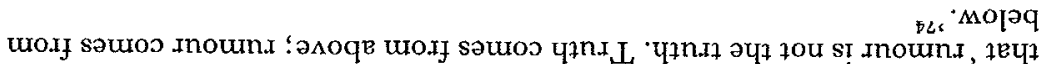

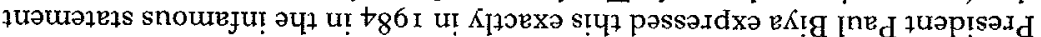

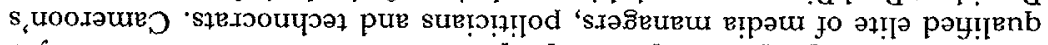

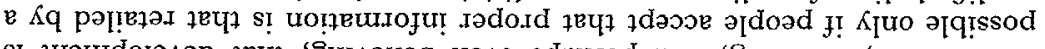

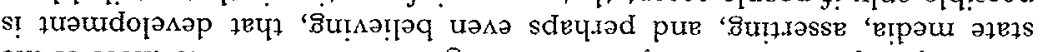

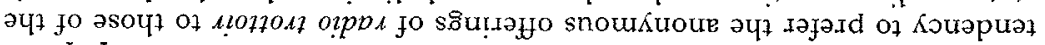

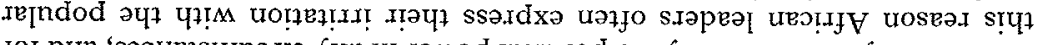

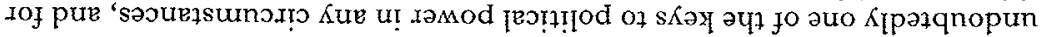
sI นo!feunofu! fo [Oдfuo

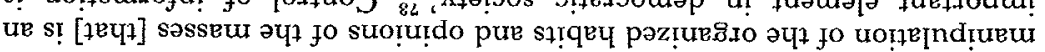




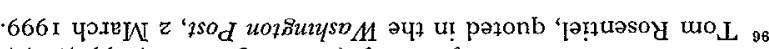

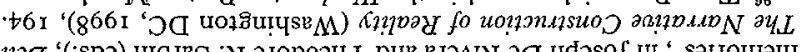

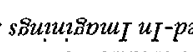

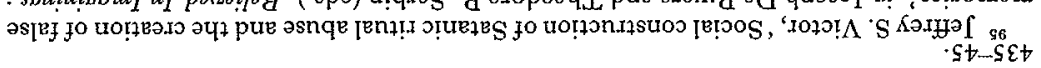

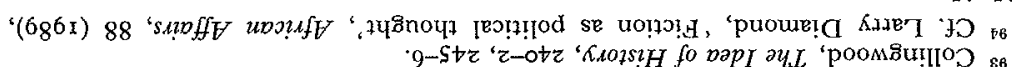

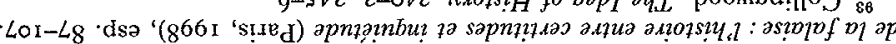

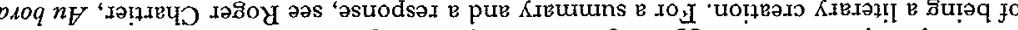

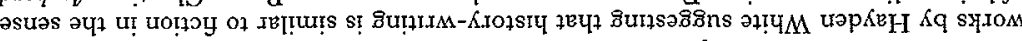

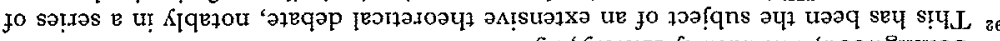

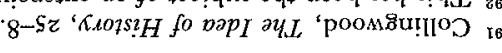

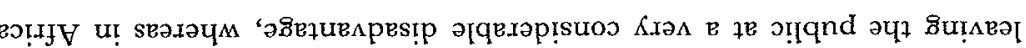

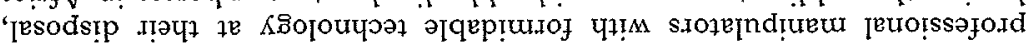

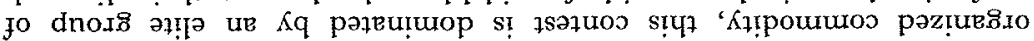

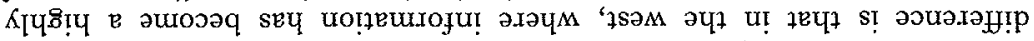
IEjn

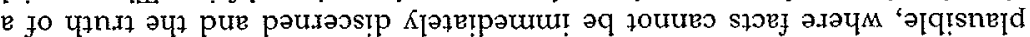

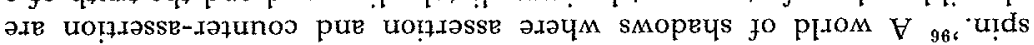

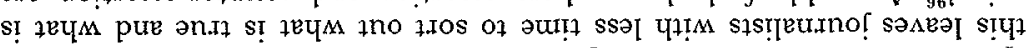

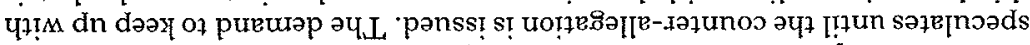

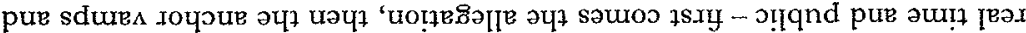

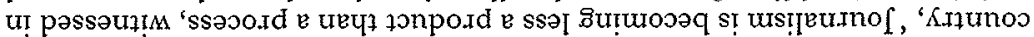

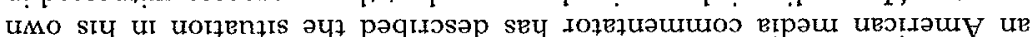

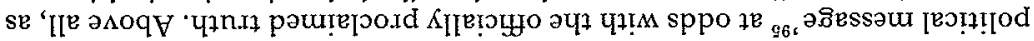

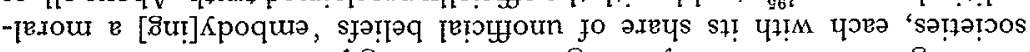

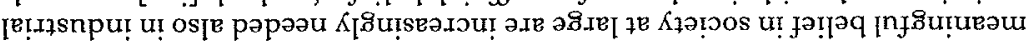

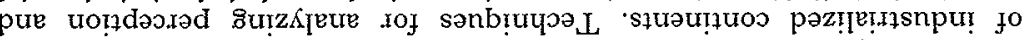

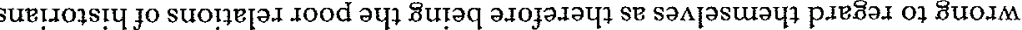

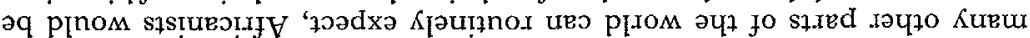

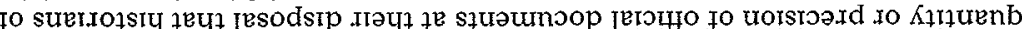

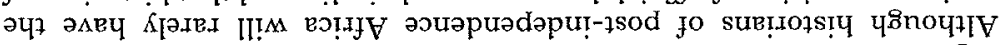

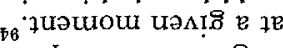

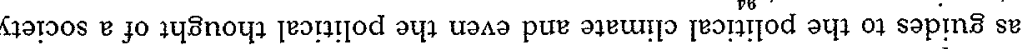

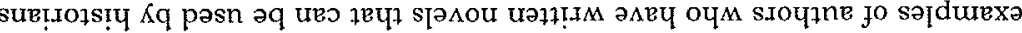

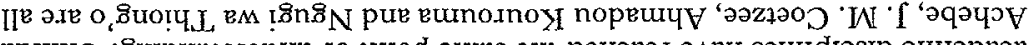

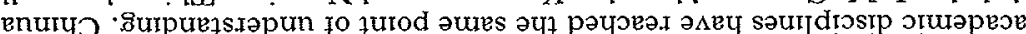

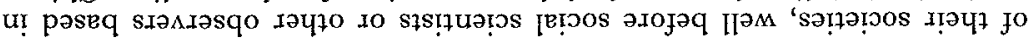

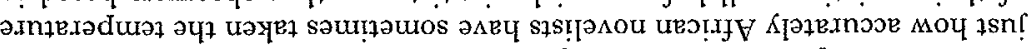

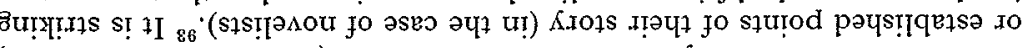

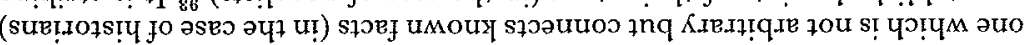

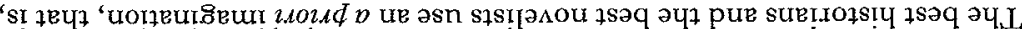
8. 'uorpeu!

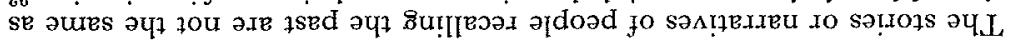

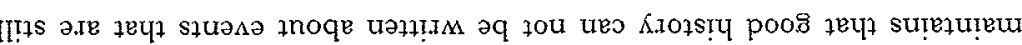

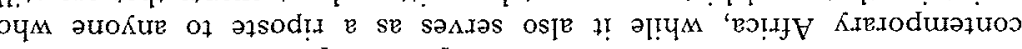

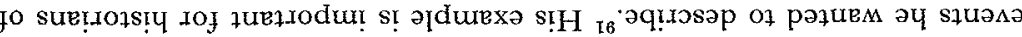

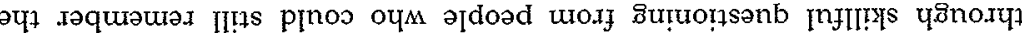

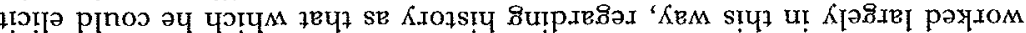

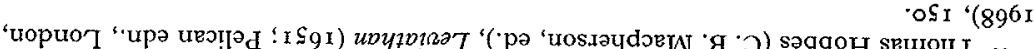

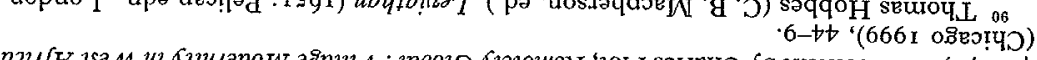

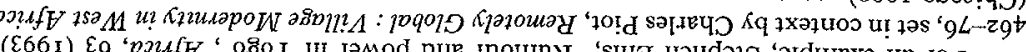

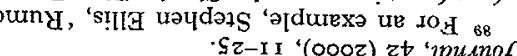

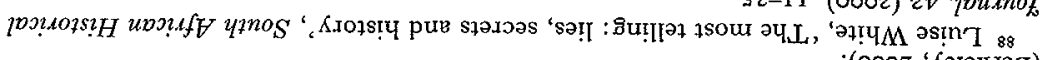

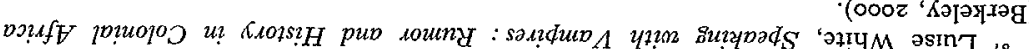
$\varepsilon^{-\varepsilon_{1}}$

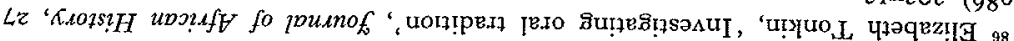

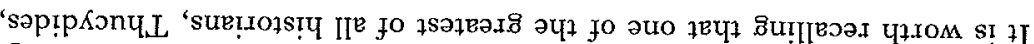

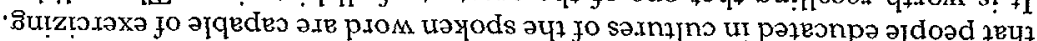

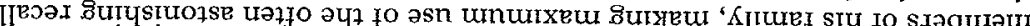

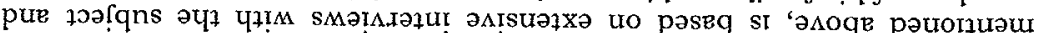

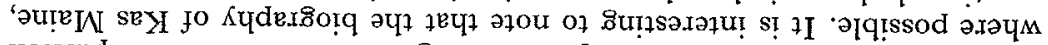

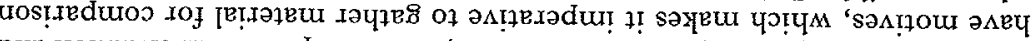

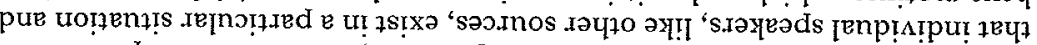

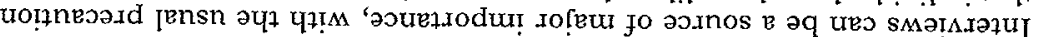

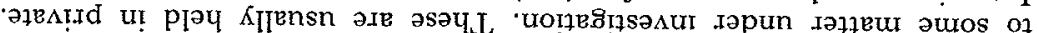

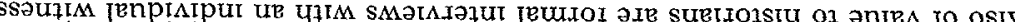

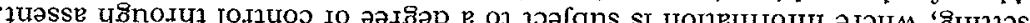

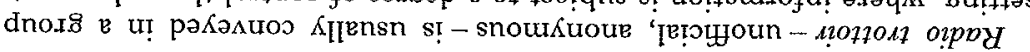
06 ; uolpozord

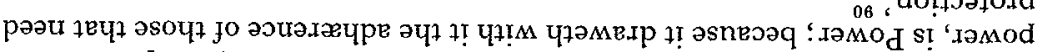

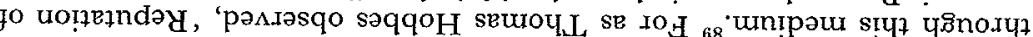

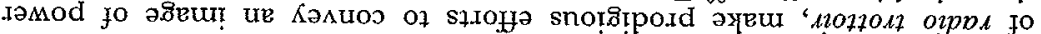

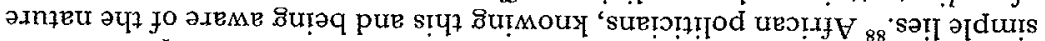

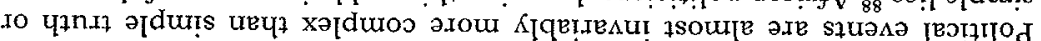

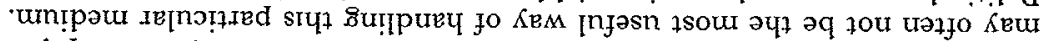

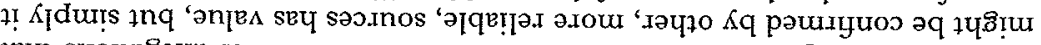

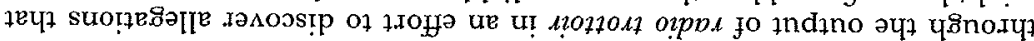
чorkas $V$ ' '

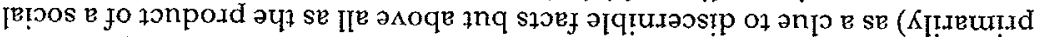

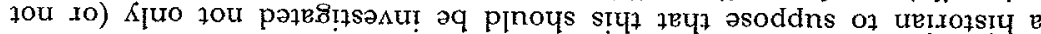

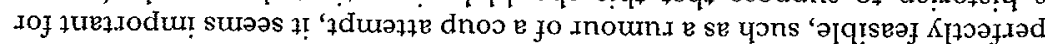

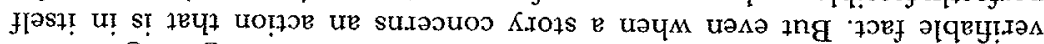

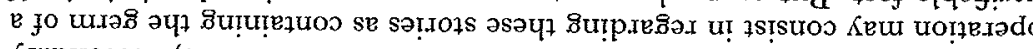

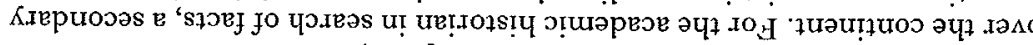

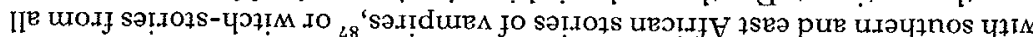

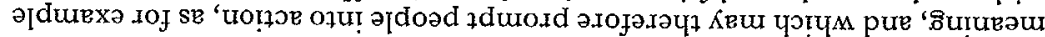

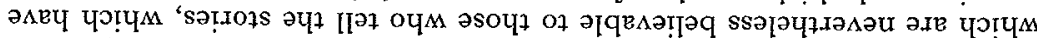

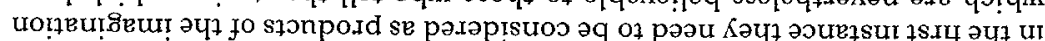

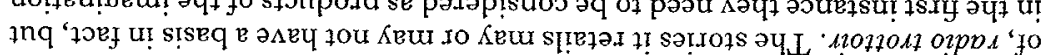

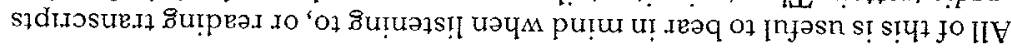

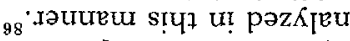

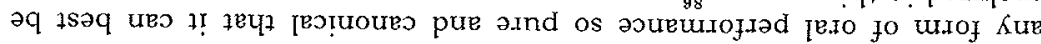

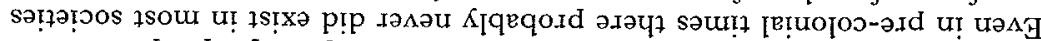

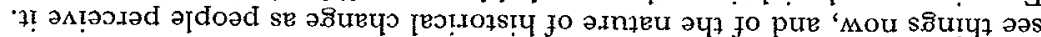

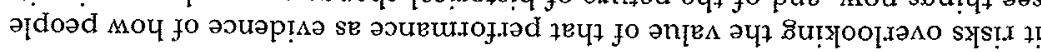

SI T79 NGHdGLS 


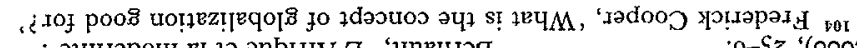

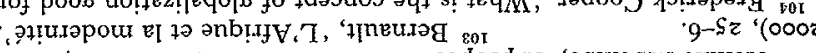

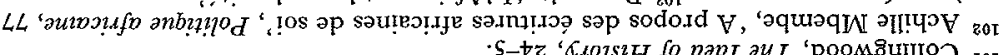

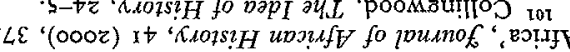

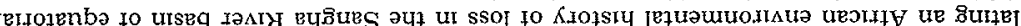

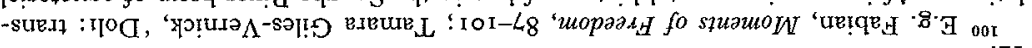

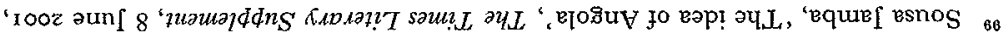

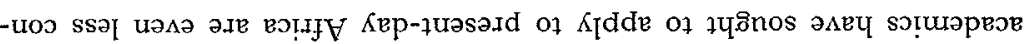

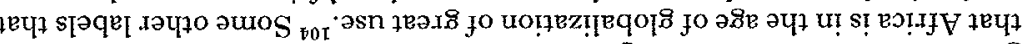

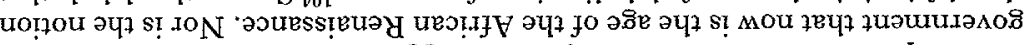

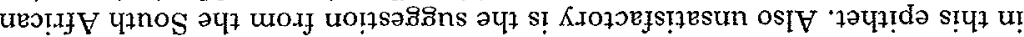

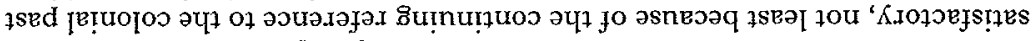

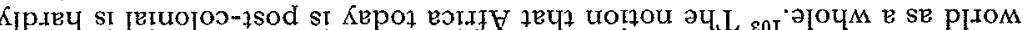

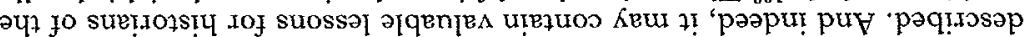

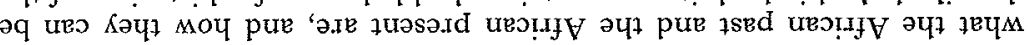

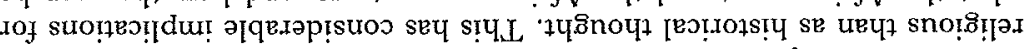

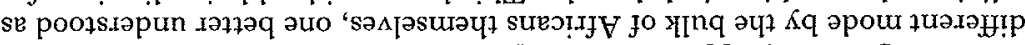

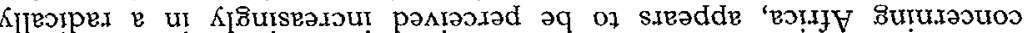

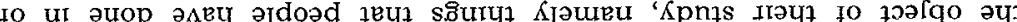
10 u (1)

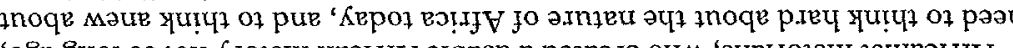

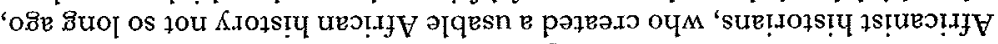

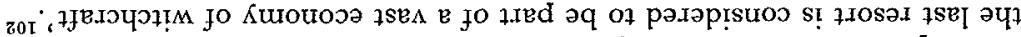

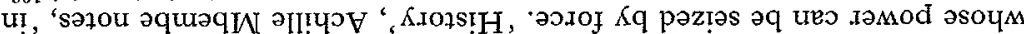

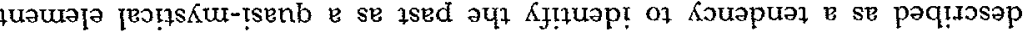

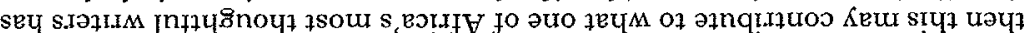

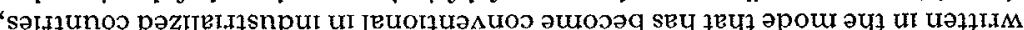

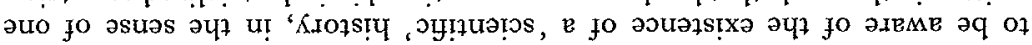
o.8е uo!̣

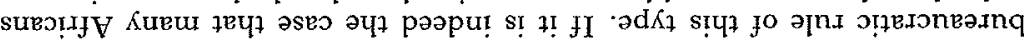

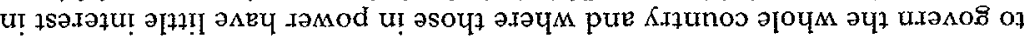

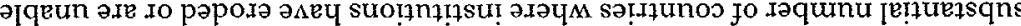

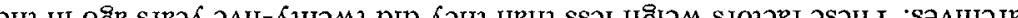

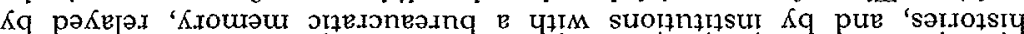

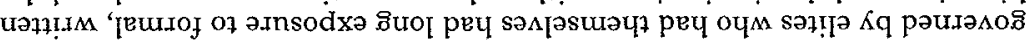

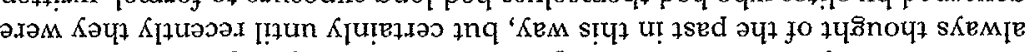

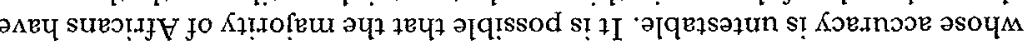

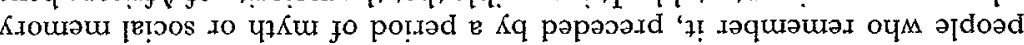

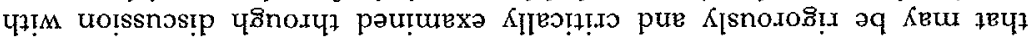
4

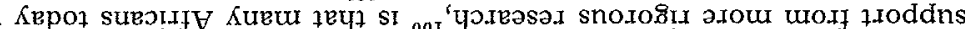

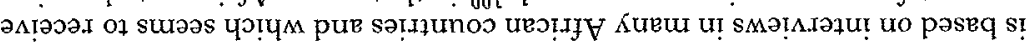

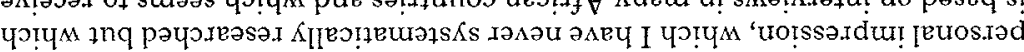
$\forall$. 20 r f

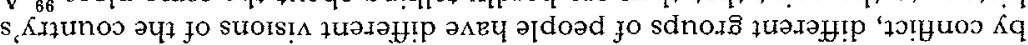

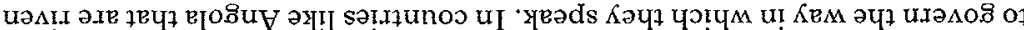

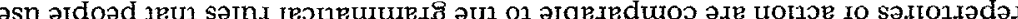

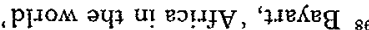

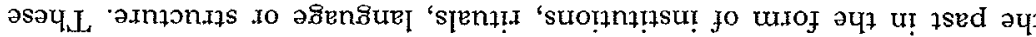

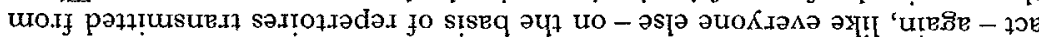

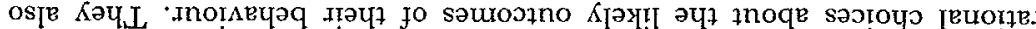

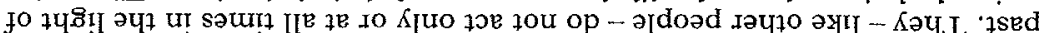

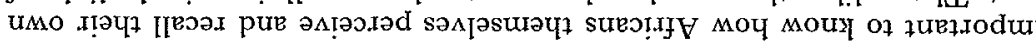

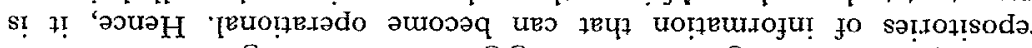

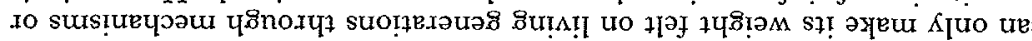

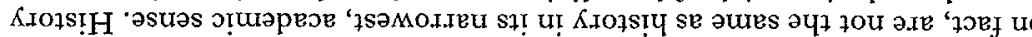

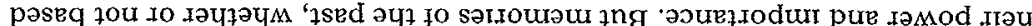

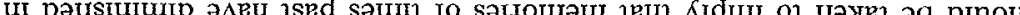

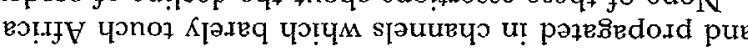

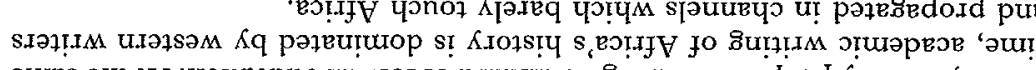

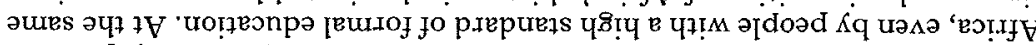

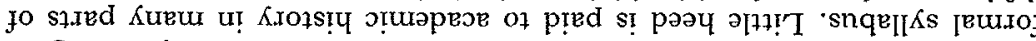

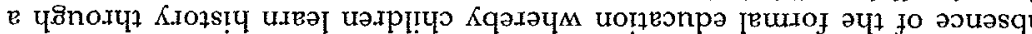

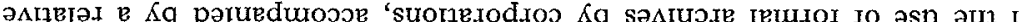

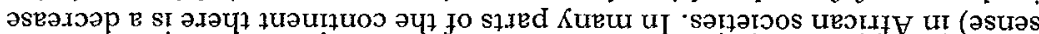

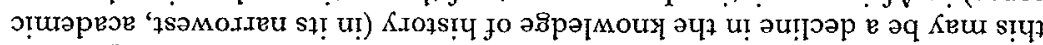

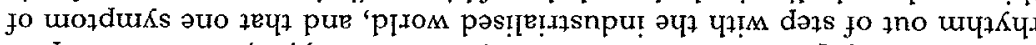

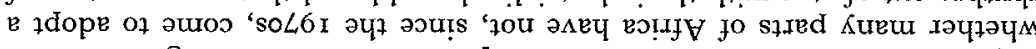

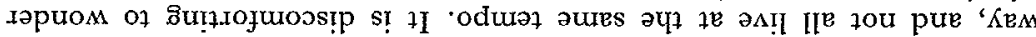

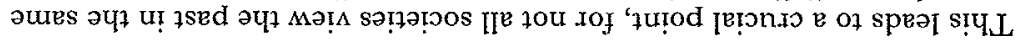

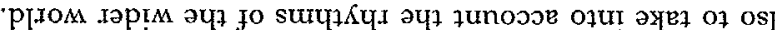

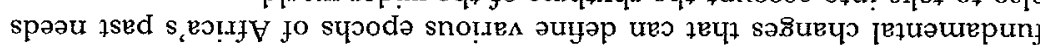

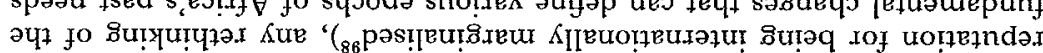

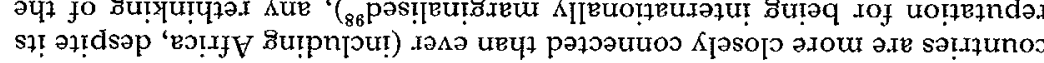

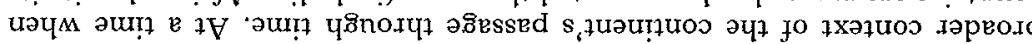
$\mathrm{B}$ ołu! us! [e!

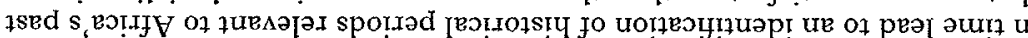
7Ч

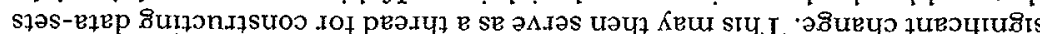

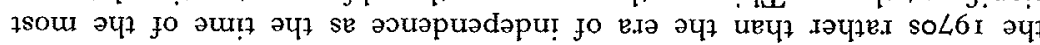

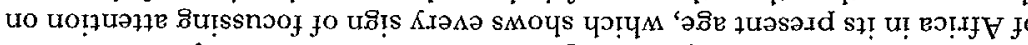
Іаұวв.деч

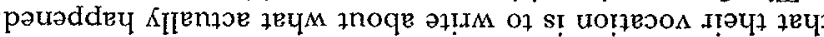

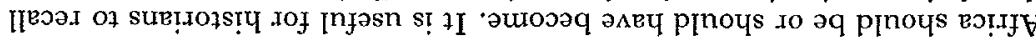

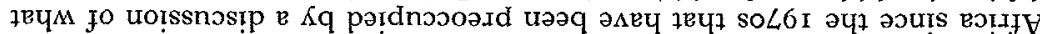

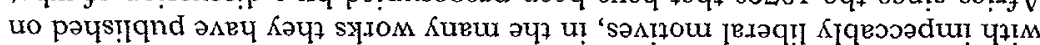

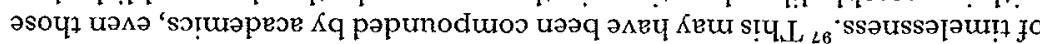

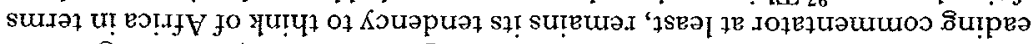

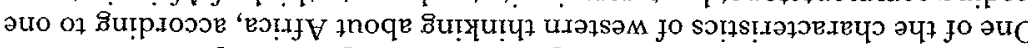

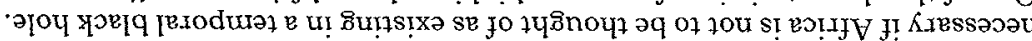

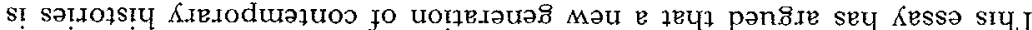

$$
\text { GWIL HO SQUVGNYS }
$$

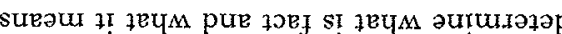

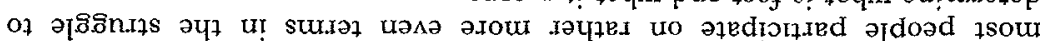


vincing, such as the suggestion by two prominent anthropologists that Africa is entering what they term 'the Age of Futilitarianism', sald to be the period 'wherein postmodern pessimism runs up against the promises of late capitalism'. 105 The problem with this formulation, other than its lack of elegance, is precisely its lack of historical precision, whereas Africa needs more than ever a contemporary history that is sensitive to the depth of time.

It is no longer an age of development or national liberation in Africa. The discussion is open as to what sort of an age it really is, in the sense of determining the characteristics that distinguish Africa now from Africa in the last identifiable period. Perhaps one should think less in terms of African history and more in terms of a world history in which Africa has its part. 'All the labels we put on periods are ex post facto; the character of an epoch can only be perceived by those looking back on it from outside. That is why we must be content for the present with a provisional name for the "postmodern" period in which we live', Barraclough wrote in 1964 , in a strikingly early use of the term 'post-modern'. ${ }^{106}$ It is already possible to see a dividing line in Africa's history in the I970s, and even if the character of the current age is unclear, at least that of the one preceding it should by now have become easier to grasp. But it would be frivolous merely to think of names that, like advertising slogans, are designed primarily to stick in the mind. The main task at hand is to inquire into the nature of recent times diligently and, above all, without the burden of past expectations. It may then turn out that, for all the terrible events and formidable problems of recent years, it is not an age of nihilism.

105 Jean and John L. Comaroff, 'Occult economies and the violence of abstraction: notes from the South African postcolony', American Ethnologist, 26 (I999), 279

${ }^{106}$ Barraclough, An Introduction to Contemporary History, I 5. 